Federal Reserve Bank of Minneapolis

Research Department

\title{
Efficiency with Endogenous Population Growth
}

\author{
Mikhail Golosov, Larry E. Jones, and Michèle Tertilt* \\ Working Paper 630
}

January 2004

\begin{abstract}
In this paper, we generalize the notion of Pareto-efficiency to make it applicable to environments with endogenous populations. Two efficiency concepts are proposed, $\mathcal{P}$-efficiency and $\mathcal{A}$-efficiency. The two concepts differ in how they treat people who are not born. We show how these concepts relate to the notion of Pareto-efficiency when fertility is exogenous. We then prove versions of the first welfare theorem assuming that decision making is efficient within the dynasty. Finally, we give two sets of sufficient conditions for noncooperative equilibria of family decision problems to be efficient. These include the Barro and Becker model as a special case.
\end{abstract}

*Golosov, University of Minnesota and Federal Reserve Bank of Minneapolis; Jones, University of Minnesota and Federal Reserve Bank of Minneapolis; Tertilt, Stanford University. We would like to thank Ed Prescott and Igor Livshits for helpful discussions, the National Science Foundation and the Federal Reserve Bank of Minneapolis for financial support, and seminar participants at the 2003 Summer Workshop on "Income and Productivity Disparity Across Countries" in Rio, Brazil, the Federal Reserve Bank of Minneapolis, and the Stanford Macro Lunch for comments. Comments are welcome: golosov@econ.umn.edu, lej@econ.umn.edu, tertilt@stanford.edu. The views expressed herein are not necessarily those of the Federal Reserve Bank of Minneapolis or the Federal Reserve System. 


\section{Introduction}

Is the population growth rate too high in sub-Saharan Africa? Is it too low in Sweden? These questions are simply the most recent manifestation of two long-standing questions in economics and moral philosophy - What is the optimal population size for society? Will individual choice of fertility lead to the right size population? (See Malthus (1798), Bentham (1948), and Mill (1965) for examples. Zimmermann (1989) contains an excellent summary of the historic debate.)

Interest in the determinants of the equilibrium path for population has increased recently. (See Becker and Barro (1988), Barro and Becker (1989), Doepke (2001), Fernandez-Villaverde (2001), Boldrin and Jones (2002), and Tertilt (2003). See Nerlove and Raut (1997) for a survey.) Surprisingly, little of this literature has used the tools of modern welfare economics (for example, Debreu (1962)) to address the normative questions that arise, in part because the usual notion of Pareto-efficiency is not well defined for environments in which the population is endogenous. To illustrate this, consider the following example. Compare an allocation with two agents, who both consume one unit of the consumption good, with one where only one agent is alive, but consumes two units of the consumption good. Is one allocation Pareto-superior to the other? Pareto-efficiency would involve a comparison of the two allocations for each person. But since different numbers of people exist in the two allocations, such a person-by-person comparison seems impossible.

In this paper, we generalize the notion of Pareto-efficiency to make it applicable to environments with endogenous populations. Three different efficiency 
concepts are analyzed: $\mathcal{P}$-efficiency, $\mathcal{A}$-efficiency, and sequential $\mathcal{P}$-efficiency. The first two of these differ in the way that the unborn are treated. ${ }^{1}$ In the first, $\mathcal{P}$-efficiency, unborn children are treated symmetrically (i.e., they have utility functions, etc.) with the born agents, but with a limited choice set. In the second, $\mathcal{A}$-efficiency, efficiency is defined only through comparisons among agents that are born. (Hence, it is not necessary that the unborn have well defined utility functions.) Sequential $\mathcal{P}$-efficiency is a dynamic refinement of $\mathcal{P}$-efficiency. We show how these three concepts relate to the notion of Pareto-efficiency when fertility is exogenous. We then prove versions of the first welfare theorem for each of them. We also derive some results regarding the existence of efficient allocations and planning problems characterizing the set of efficient allocations.

To do this, we provide a fairly general, general equilibrium formulation of fertility choice. Naturally, such a formulation will be embedded in an overlapping generations framework. Each decision maker has a fixed set of potential children and decides how many of them will be born. Models of fertility will also naturally involve some external effects across agents in the economy. We allow for a rich set of potential consumption external effects within a family or dynasty, running both from parent to child (and grandchild, etc.) and from

\footnotetext{
${ }^{1}$ Throughout, we do not take a stand on how to evaluate the utility of the unborn. (Indeed, such a task is well beyond the scope of this paper.) Rather, we propose two alternative definitions of Pareto-optimality in the context of endogenous fertility. They are at opposite extremes of the spectrum of treatments of the unborn: one treats them symmetrically with born agents; the other assumes that they do not enter efficiency considerations beyond whatever weight they receive from their parents (or born siblings, etc.). For either notion, a version of the first welfare theorem holds.
} 
child to parent. This includes the Barro and Becker (1989) formulation of fertility along with many others.

In addition to this standard utility externality, we include another more subtle one. This is that, from the point of view of the potential children, this is a model in which their choice set is dependent on the actions of other agents in the economy. If the parent chooses that they will not be born, they have effectively no choices. If, on the other hand, the parent chooses that they will be born, they face a standard, nontrivial choice set.

We assume that it is costly to have children. This means that parents bear a cost for changing their children's choice set. Thus, an important interaction effect between the two external effects is included. That is, without the consumption external effect, parents may not have an incentive to enlarge their children's choice set.

As is usual in models with external effects, there is no presumption that equilibrium individual behavior will aggregate to an efficient outcome. However, in models of fertility, it is commonly assumed that mechanisms exist for transfers inside the family. Following this logic, we divide the efficiency question into two pieces: efficient transfer systems within a dynastic family and efficient trade across dynasties. First, we show using standard arguments that if all trade across dynasties is done at common, parametric prices and there are no external effects across families, equilibrium is efficient as long as the dynasty problem is solved efficiently internally. Second, we give sufficient conditions for a noncooperative implementation of the dynastic game to be efficient. We show two extreme cases that guarantee efficiency of the family game. In the first case, dynasties are perfectly altruistic, which eliminates 
the potential time consistency problem among family members and thereby assures efficiency. This includes the Barro-Becker model as a special case. In the second case, if contracts between parents and children are rich enough, so that parents can effectively dictate their children's actions, then efficiency is also guaranteed, irrespective of the preference details. Other games and preference specifications may lead to equilibrium inefficiencies. We provide examples to illustrate what can go wrong.

Our approach allows us to easily distinguish between two potential causes of overpopulation that have been at the center of the more recent debates on population. The first of these is the existence of scarce factors and the 'crowding' of these factors that results when the population is 'large.' The second is the potential increase in pollution (e.g., emission of greenhouse gases) as population grows. We find that scarce factors do not, in and of themselves, give rise to inefficiencies in population. Rather, they are a "pecuniary externality' whose effects are manifested in price changes. This is similar to the arguments made in Willis (1987) and Lee and Miller (1990). In contrast, if true external effects exist that are related to population size, not surprisingly, individual choices do not necessarily lead to efficient population sizes. This is true both when the external effects are negative, like pollution, and when they are positive, as some authors model knowledge (Romer 1987) or human capital (Lucas 1988). ${ }^{2}$ Because of their structure, these examples suggest that although population growth rates may be too high in the presence of negative

\footnotetext{
${ }^{2}$ Interestingly, Keynes was one of the first authors to argue that population growth was too low in England in the 1920s and that this was a cause for a reduction in inventive activity and hence stagnation. (See Zimmermann 1989)
} 
external effects, this is only a statement that overall population is too high, not that African or Swedish population is.

To summarize, our findings suggest the following typology for inefficiencies when fertility is endogenous. (They are not mutually exclusive.)

1. The family is using the 'wrong' efficiency concept internally; for example they are $\mathcal{A}$-maximizing and 'should be' $\mathcal{P}$-maximizing.

2. The family is using the 'right' criterion, but for standard reasons based on interactions among individuals, the first welfare theorem fails. Examples include external effects, public goods, congestion effects, missing markets, and private information.

3. Limitations on bequests, lack of perfect altruism, and so on, cause the family allocation to not be $\mathcal{P}$-maximizing (or $\mathcal{A}$-maximizing).

A small recent literature addresses the question of optimal populations formally. ${ }^{3}$ Willis (1987) also attempts to analyze whether general equilibrium models with endogenous fertility lead to Pareto-efficient allocations. Willis does this, however, without formally defining Pareto-efficiency for these environments. Instead, Willis studies the solution to a planning problem and shows under what it coincides with a competitive equilibrium. Nerlove, Razin,

\footnotetext{
${ }^{3} \mathrm{~A}$ separate line of research on endogenous populations derives from the social choice literature. There, authors use an axiomatic approach to derive representation theorems for social orderings which include population size as one of the choices. See Blackorby, Bossert, and Donaldson (1995) for one such paper and Section 6 of Blackorby, Bossert and Donaldson (2002) for a survey of this approach.
} 
and Sadka (1987, 1989) and Razin and Sadka (1995) have an agenda similar to ours. They mention the difficulty of defining efficiency in endogenous population environments and establish the need for a new concept. However, rather than developing a generalization of Pareto-optimality, they turn to a characterization of the optimal population under two alternative social welfare functions: the maximization of average utility and the maximization of the sum of utilities in a society. Such criteria, however, typically give one optimal allocation and are very different in spirit from an efficiency concept that usually contains a large number of allocations. Schweizer's (1996) paper is most directly related to ours. He proposes an ordinal welfare criterion, which is based on a type-by-type comparison of various allocations. Versions of the first and second welfare theorems for the new concepts are shown to hold under certain conditions. This concept is defined only for symmetric steady-state allocations. In this sense, our concept is significantly more general. ${ }^{4}$

Finally, a few authors have pointed out various reasons for why the private and social costs of having children could differ. These papers all provide an informal discussion of what types of externalities could arise in the context of fertility choice. (Examples are Friedman (1972), Chomitz and Birdsall (1991), Lee and Miller (1991), and Simon (1992).) However, none of these papers provides a formal concept or the tools to thoroughly address the efficiency question.

The remainder of our paper is organized as follows. In Section 2, we introduce notation. In Section 3, we give definitions of our two notions of

\footnotetext{
${ }^{4}$ See Michel and Wigniolle (2003) for another approach that is similar to ours but substantially less general.
} 
Pareto-optimality, give some simple examples and discuss some preliminary properties. Section 4 contains the development of the analog of the first welfare theorem for settings in which population is endogenous and the decisionmaking unit is a family. In Section 5, we show that the Barro and Becker (1989) model of fertility choice is one example of a model in which our form of dynastic maximization holds and hence population is efficient. Section 6 is devoted to discussing various examples of what might cause family maximization to fail, and Section 7 concludes.

\section{Notation and Feasible Allocations}

We consider an overlapping generations economy, where each generation makes decisions about fertility. Each agent is assumed to live only for one period. The initial population in period 0 is denoted by $\mathcal{P}_{0}=\{1, \ldots, N\}$. Each person can give birth to a maximum of $\bar{f}$ children. ${ }^{5}$ For each period $t$, a potential population $\mathcal{P}_{t}$ is defined recursively as $\mathcal{P}_{t} \equiv \mathcal{P}_{t-1} \times \mathcal{F}$, where $\mathcal{F}=\{1, \ldots, \bar{f}\}$, and we denote by $\mathcal{P}$ the population of all agents potentially alive at any given date. Then, an individual born in period $t$ is indexed by $i^{t} \in \mathcal{P}_{t}$ and can be

\footnotetext{
${ }^{5}$ Throughout most of the paper, we will assume that the number of children possible is discrete. This assumption makes the ideas we discuss simpler to implement, but does not come without costs. It introduces indivisibilities in the choice sets of individual agents, and this property brings with it some technical difficulties. (See for example the discussion on $\mathcal{A}$ efficiency below.) Many of the models of fertility choice (e.g., Barro and Becker (1989)) allow for non-integer choices. Much of the analysis presented here can be done in this framework as well. See Section 5 for an example. Finally, note that we assume that individuals have children, not couples. This is done to simplify the development that follows.
} 
written as $i^{t}=\left(i^{t-1}, i_{t}\right)$, specifying that $i^{t}$ is the $i_{t}$ th child of the parent $i^{t-1}$. We often simply write $i$ as the length of the vector already indicates the period in which the agent was born.

We assume that there are $k$ goods available in each period. There is one representative firm, which behaves competitively. The technology is characterized by a production set: $Y \subset \mathbb{R}^{k \infty}$. In other words, an element of the production set is an infinite sequence of $k$-tuples that describes feasible inputoutput combinations. Note that goods are defined in a broad sense here. They can include labor, leisure, capital stock, etc. An element of the production set is denoted by $y \in Y$. We can write $y=\left\{y_{t}\right\}_{t=0}^{\infty}$, where $y_{t}=\left(y_{t}^{1}, \ldots, y_{t}^{k}\right)$ is the projection of the production plan onto time $t$.

An allocation is $(z, y)$, where $z=\left(z_{1}, \ldots, z_{N}, z_{(1,1)}, \ldots z_{(N, \bar{p})}, \ldots\right)$, with $z_{i}=\left(x_{i}, f_{i}^{1}, \ldots, f_{i}^{\bar{f}}\right)$ for each agent $i \in \mathcal{P}_{t}$. The interpretation is that $x_{i} \in \mathbb{R}^{k}$ is $i$ 's consumption and $f_{i}^{j} \in\{0,1\}, j=1, \ldots, \bar{f}$, is $i$ 's fertility choices: $f_{i}^{j}=1$ means child $j$ is born, and $f_{i}^{j}=0$ means child $j$ is not born.

Each allocation implicitly defines a subset of the potential population that is actually born. Given an allocation $(z, y)$, let $I_{t}(z)$ be the set of people born in period $t$. (Note that this depends only on $z$ and not on $y$.) Formally,

$$
I_{t}(z)=\left\{i^{t}=\left(i^{t-1}, i_{t}\right) \in \mathcal{P}_{t} \text { s.t. } f_{i^{t-1}}^{i_{t}}=1\right\}
$$

Let $I(z)$ be the set of people who are alive at some point in time; that is, $I(z)=\bigcup_{t} I_{t}(z)$.

We assume that each (potential) agent is described by both an endowment of goods and a utility function. We will use the notation $\left(e_{i}, 0, \ldots, 0\right) \in \mathbb{R}^{k} \times \mathcal{F}$ to denote individual $i$ 's endowment. Note that we have assumed that individ- 
uals are endowed with no children.

To simplify, we assume that preferences are described by a utility function, denoted by $u_{i}(z)$ which we allow to depend on the entire allocation. We do this to allow for the possibility of external effects across members of a family. When it is important to distinguish the choices individual $i$ makes from the rest of the allocation, we will use the notation $u_{i}\left(x_{i}, f_{i}, z_{-i}\right)$. Below, we will place restrictions on the extent to which $u_{i}$ can depend on $z_{-i}$.

An important, qualitative assumption is implicit in this construction: we have assumed that all agents, even those who are not born, have well-defined preferences. But, of course, it is not clear what the utility of the unborn should be. There is a long-standing debate in the moral philosophy literature about how this problem should be handled. (See for example Singer (1993).) As will become clear, how this issue is resolved will partly determine which allocations are efficient and which are not. Our strategy therefore is to model the utility of an unborn person in a very general way and ultimately to let the researcher pick a formulation appropriate for a specific problem. Our general formulation includes the following examples:

$$
\begin{aligned}
& u\left(z_{i}, f_{i}, z_{-i}\right)=f_{i^{t-1}}^{i_{t}} u\left(z_{i}, f_{i}\right) \\
& u\left(z_{i}, f_{i}, z_{-i}\right)=u\left(z_{i}\right)+\beta \sum_{j=1}^{\bar{f}} f_{i}^{j} u\left(z_{(i, j)}, f_{(i, j)}\right) \\
& u\left(z_{i}, f_{i}, z_{-i}\right)= \begin{cases}u\left(z_{i}, f_{i}\right) & \text { if } f_{i^{t-1}}^{i_{t}}=1 \\
\bar{u} & \text { if } f_{i^{t-1}}^{i_{t}}=0\end{cases} \\
& u\left(z_{i}, f_{i}, z_{-i}\right)=f_{i}^{j} u\left(z_{(i, j)}\right)+\alpha \sum_{k=1}^{\bar{f}} f_{i}^{k} u\left(z_{(i, k)}, f_{(i, k)}\right)
\end{aligned}
$$

In the first example, the utility of an unborn person is normalized to zero. The 
second example is one of an altruistic utility function, where parents derive utility only from their born children. In the third example, the utility of an unborn person is a constant, but may or may not be higher than the utility from a particular consumption bundle of a born person. In the last example, unborn people derive utility from their born siblings.

For the most part, the entirety of the theory can be developed without making any specific assumptions about what these preferences are like, however, and this will be the strategy that we adopt. When discussing particular examples, it will be necessary to go into more detail, of course.

Each individual has a consumption set which, as is standard in models with external effects, is allowed to depend on the choices of other agents. Since we want to focus on modeling fertility decisions, we will restrict this dependence across agents to the fertility choices of the agent's parents, grandparents, etc. In particular, we assume that the consumption set of an unborn agent contains only one element, his endowment. Note that this assumption is made for convenience only and does not contain any content. With this convention, unborn people can always be included in feasibility constraints and family budget constraints, since they cancel out by construction. Formally, we write

$$
z_{i^{t}} \in Z_{i^{t}}\left(z_{-i^{t}}\right)= \begin{cases}\left(e_{i^{t}}, 0, \ldots, 0\right) & \text { if } f_{i^{t-1}}^{i_{t}}=0 \\ \hat{Z} & \text { if } f_{i^{t-1}}^{i_{t}}=1\end{cases}
$$

where $\hat{Z} \subseteq \mathbb{R}^{k} \times\{0,1\}^{\bar{f}}$. Note that the dependence of the consumption set on other people's choices is of a very limited nature. In particular, only the fertility decision of a person's ancestors is relevant. This means that if a person is born, no further choices of other agents affect the consumption set of that 
person. Depending on the details of the model, $\hat{Z}$ can be defined so that it embodies certain joint restrictions on the consumption and fertility choices of the individual. For example, it is natural to assume that child bearing takes time directly from the parents, and so it may not be possible to have 10 children and still consume, or supply to the labor market, the full endowment of leisure. Note that we have assumed that $\hat{Z}$ does not depend on the choices of other agents beyond this. It is also natural to assume that $\left(e_{i}, 0, \ldots, 0\right) \in Z_{i}\left(z_{-i}\right)$ for all $i$ and all $z_{-i}$.

Since this formulation of consumption sets is static in nature, it does not allow for the possibility of capital formation inside the households. This possibility can be modeled included it in the production set, however.

Most models of fertility also have a transferable cost of child production. Let $c\left(f_{i}\right) \in \mathbb{R}_{+}^{k}$ be the goods cost, as a function of person $i$ 's fertility choice.

Assumption $1 c(0)=0$, and $c(f)$ is strictly increasing in $f$.

We can now define feasibility for this environment.

Definition 1 An allocation $\{z, y\}$ is feasible if

1. $z_{i} \in Z_{i}\left(z_{-i}\right)$, for all $i$,

2. $\sum_{i \in \mathcal{P}_{t}} x_{i}+\sum_{i \in \mathcal{P}_{t}} c\left(f_{i}\right)=\sum_{i \in \mathcal{P}_{t}} e_{i}+y_{t}$ for all $t$.

3. $y \in Y$.

This formulation, as general as it seems, is missing some obvious details. We assume that individuals live for only one period and that fertility decisions are made by individuals, not couples. These choices are made to keep the notational burden to a manageable level. 


\section{$3 \quad$ Efficient Allocations}

The discussion above turns models with an endogenous set of agents into one with a fixed set of agents, but with restrictions on what unborn agents can choose and external effects in preferences. An advantage of this construction is that we can use, as a first cut, the normal notion of Pareto-efficiency. We call this concept $\mathcal{P}$-efficiency, where $\mathcal{P}$ refers to populations. This concept treats born and unborn people symmetrically. It is not clear, however, that this is the best way of thinking about the issue. Alternatively, one might consider concepts that treat born and unborn asymmetrically. Consider again the example from the introduction, in which the only feasible allocations are one person alive consuming one unit of the consumption good and two people alive consuming 0.5 units each. Call these two allocations $z$ and $\hat{z}$, respectively. Any reasonable definition of efficiency should include the $z$ allocation among its efficient allocations, because the only other feasible allocation makes an agent who is always alive strictly worse off. However, whether one would also like the second allocation to be efficient is debatable. On the one hand, one could argue that going from $\hat{z}$ to $z$ makes one person strictly better off and no one worse off as the second person is not alive under $z$. This would then make $z$ superior to $\hat{z}$, and hence $\hat{z}$ would be inefficient. Alternatively, associating low

utility with not being alive (say 0) and factoring unborn people into the utility comparison would lead one to argue that $\hat{z}$ is also efficient, as $z$ would make person 2 strictly worse off. These two perspectives differ in their treatment of born and unborn people. Since it's not obvious what the right perspective is, we will provide two efficiency concepts, one that treats born and unborn people 
symmetrically $(\mathcal{P}$-efficiency) and another that treats them very $\operatorname{differently}(\mathcal{A}$ efficiency).

\section{$3.1 \quad \mathcal{P}$-efficiency}

$\mathcal{P}$-efficiency does not distinguish between agents who are born and not born in its treatment beyond what is implicit in feasibility and preferences. It is defined as follows.

Definition 2 A feasible allocation $(z, y)=\left(\left\{\left(x_{i}, f_{i}\right)\right\}_{i \in P}, y\right)$ is $\mathcal{P}$-efficient if there is no other feasible allocation $(\hat{z}, \hat{y})$ such that

1. $u_{i}\left(\hat{x}_{i}, \hat{f}_{i}, \hat{z}_{-i}\right) \geq u_{i}\left(x_{i}, f_{i}, z_{-i}\right)$ for all $i \in \mathcal{P}$

2. $u_{i}\left(\hat{x}_{i}, \hat{f}_{i}, \hat{z}_{-i}\right)>u_{i}\left(x_{i}, f_{i}, z_{-i}\right)$ for at least one $i \in \mathcal{P}$.

\subsubsection{Examples}

Following, we give some simple examples of what it means for an allocation to be $\mathcal{P}$-efficient. Consider a two period setting with only one agent alive in the first period. Assume that $\bar{f}=2$ so that only two potential children can be born. Thus, the set of potential agents is $\mathcal{P}_{0}=\{1\}, \mathcal{P}_{1}=\{1,2\}$, $\mathcal{P}=\{1,(1,1),(1,2)\}$.

Assume that there are two goods, consumption, $c$, and time, $\ell$, so that $k=2$ and that the parent as well as each potential child is endowed with $\ell^{e} \geq 0$ units of time. Assume there is no utility from leisure, and therefore time is either supplied in the market, $\ell$, or used for childrearing. It takes $\theta>0$ units of time to birth a child. For simplicity, assume there is no goods cost 
of having a child. Since agents $i=(1,1),(1,2)$ cannot have children, they trivially supply their entire endowment of time to the market $\ell_{i}=\ell^{e}$, if born.

The production function is assumed to be static with $c=F\left(\ell^{f}\right)=w \ell^{f}$, where $\ell^{f}$ is the amount of labor hired by the firm. An allocation can then be described by the vector $z=\left(c_{1}, \ell_{1}, f_{1}, f_{2} ; c_{(1,1)}, \ell_{(1,1)}, c_{(1,2)}, \ell_{(1,2)}\right)$.

Utility of agent 1 is given by

$$
u_{1}(z)=u\left(c_{1}\right)+\beta\left[f_{1} u\left(c_{(1,1)}\right)+f_{2} u\left(c_{(1,2)}\right)\right],
$$

where $u$ is strictly increasing and concave with $u(0)=0$, and $0<\beta<1$ is a discount factor determining the weight that a parent puts on its child's consumption. Note that we have assumed that the two children are treated symmetrically and that the parent gets 0 utility for children who are not born. The utility of the potential children is given by

$$
u_{(1, i)}(z)=u\left(c_{(1, i)}\right)
$$

This is basically a two period version of the Barro and Becker model without capital. Feasibility in this simple environment requires that

$$
c_{1}=w\left[\ell^{e}-\theta\left(f_{1}+f_{2}\right)\right]
$$

that

$$
f_{1} c_{(1,1)}+f_{2} c_{(1,2)} \leq w\left(f_{1}+f_{2}\right) \ell^{e}
$$

and that each agent be assigned an element of his consumption set, i.e., $c_{(1, i)}=0$, and $\ell_{(1, i)}=\ell^{e}$ if $f_{i}=0$.

Examples of Efficient and Inefficient Populations:

Consider the four distinct allocations, $z^{*}, \hat{z}, \tilde{z}$, and $\breve{z}$ defined by:

$$
z^{*}=\left(w \ell^{e}, 0,0,0 ; 0, \ell^{e} ; 0, \ell^{e}\right),
$$




$$
\begin{aligned}
& \hat{z}=\left(w\left(\ell^{e}-\theta\right), 0,1,0 ; w \ell^{e}, 0 ; 0, \ell^{e}\right), \\
& \tilde{z}=\left(w\left(\ell^{e}-2 \theta\right), 0,1,1 ; w \ell^{e}, 0 ; w \ell^{e}, 0\right), \\
& \breve{z}=\left(w\left(\ell^{e}-2 \theta\right), 0,1,1 ; 2 w \ell^{e}, 0 ; 0,0\right) .
\end{aligned}
$$

Assume that $\theta$ is small enough such that consumption is always interior, i.e., $\theta<\frac{\ell^{e}}{2}$. Allocation $z^{*}$ has no children being born. Allocation $\hat{z}$ has exactly one child (the first of the two possible children) born. In allocation $\tilde{z}$, both potential children are born. Finally, in allocation $\breve{z}$, both children are born, but $(1,2)$ is 'exploited' by $(1,1)$ and has no consumption. Table 1 summarizes the utilities for the 3 potential people for all four allocations. It follows immediately from the table that, irrespective of parameters, both

Table 1: Utilities for various allocations

\begin{tabular}{|l|l|l|l|}
\hline Allocation & Parent & $(1,1)$ & $(1,2)$ \\
\hline$z^{*}$ & $u\left(w \ell^{e}\right)$ & 0 & 0 \\
$\hat{z}$ & $u\left(w \ell^{e}-\theta\right)+\beta u\left(w \ell^{e}\right)$ & $u\left(w \ell^{e}\right)$ & 0 \\
$\tilde{z}$ & $u\left(w \ell^{e}-2 \theta\right)+2 \beta u\left(w \ell^{e}\right)$ & $u\left(w \ell^{e}\right)$ & $u\left(w \ell^{e}\right)$ \\
$\breve{z}$ & $u\left(w \ell^{e}-2 \theta\right)+\beta u\left(2 w \ell^{e}\right)$ & $u\left(2 w \ell^{e}\right)$ & 0 \\
\hline
\end{tabular}

$\tilde{z}$ and $\breve{z}$ are $\mathcal{P}$-efficient, since these allocations are strictly preferred to any other allocations by $(1,2)$ and $(1,1)$, respectively. In addition, depending on parameters, $z^{*}$ and $\hat{z}$ can also be $\mathcal{P}$-efficient. For example, if $\beta=0$, then $z^{*}$ is $\mathcal{P}$-efficient, since any other allocation would make the parent strictly worse off. The allocation $\hat{z}$ can also be strictly preferred by the parent (and therefore $\mathcal{P}$-efficient) for moderate values of $\beta$ and $\theta$. Generally speaking, the parent's ranking of $z^{*}, \hat{z}$, and $\tilde{z}$ depends on the weight the parent puts on children's consumption, $\beta$, the cost of raising children, $\theta$, and the concavity of $u$, along 
with the productivity of labor, as measured by $w$. From the parent's point of view, having extra children gives him additional labor in period 2, which needs to be weighted against the (utility) cost of having the child.

This shows two important things. First, any fertility level can be $\mathcal{P}$-efficient for the right choice of parameters. Second, fertility can never be inefficiently high because $\breve{z}$ and $\tilde{z}$ are always efficient independent of $\beta, \theta$, and the functional form for $u(\cdot)$. This second property is fairly general and is discussed in detail below. Also note that $\breve{z}$ is $\mathcal{P}$-efficient even though it would never be chosen by rational parents (due to strict concavity of $u(\cdot)$ ).

Next we will show that the set of efficient allocations can change if siblings care about each other. Change the utility for agents $i=(1,1),(1,2)$ to

$$
u_{i}(z)=u\left(c_{i}\right)+f_{i} \lambda u\left(c_{-i}\right), \quad \lambda>0
$$

That is, an agent who is alive derives utility from his sibling's consumption. Then if $\lambda$ is large enough, $\breve{z}$ is no longer efficient because $(1,1)$ would prefer his sibling to consume more and is willing to give up some own consumption to achieve this. Note, however, that it is still true that, irrespective of parameters, a superior allocation cannot exist that has strictly fewer people being born.

Allowing children to derive utility from their parent's utility can also alter the set of efficient allocations. Suppose that $u_{1}(\tilde{z})>u_{1}(\hat{z})$, that is, the parent strictly prefers having both children. Then it follows from Table 1 that allocation $\hat{z}$ is inefficient because $\tilde{z}$ is weakly preferred by $(1,1)$ and strictly preferred by 1 and $(1,2)$. Now change the utility function so that children (if born) derive utility from their parent's consumption:

$$
u_{(1, i)}=u\left(c_{(1, i)}\right)+f_{i} \eta u\left(c_{1}\right), \quad \eta>0
$$


Then for $\eta$ large enough, the first child $(1,1)$ strictly prefers $\hat{z}$ over any other allocation. ${ }^{6}$ But this immediately implies that $\hat{z}$ is $\mathcal{P}$-efficient, because any other allocation would make $(1,1)$ strictly worse off. In this case, $\hat{z}$ is efficient not because the parent strictly prefers having only one child, but because the loss in utility to the first child due to the reduction in the parent's consumption when having the second child is too large. This is fundamentally a time consistency problem in preferences: The parent and the first child differ in their relative assessments of the utility of the three agents.

Finally, we allow the utility of unborn children to depend on the other agents in the economy. In this case, it is no longer true that fertility cannot be too high. Change the utility function of agents $i=(1,1),(1,2)$ to

$$
u_{i}=u\left(c_{i}\right)+\eta u\left(c_{1}\right)
$$

Under this specification, agents $(1,1)$ and $(1,2)$ may prefer not being born at all. For $\eta$ and $\theta$ large enough, the children care more about the loss of direct consumption utility by the parent than they do about their own consumption, and hence, they would prefer that their parents not have children. If, in addition, $\beta$ is small, then the parent may also strictly prefer allocation $z^{*}$ over anything else, and hence for the right parameters, $z^{*}$ is the only efficient allocation. This last example shows that if we allow the utility of the unborn to vary with the consumption of other people, then fertility can be inefficiently high.

As the examples show, even in fairly simple environments, which allocations

\footnotetext{
${ }^{6}$ More precisely, $\eta>\frac{u\left(2 w \ell^{e}\right)-u\left(w \ell^{e}\right)}{u\left(w \ell^{e}-\theta\right)-u\left(w \ell^{e}-2 \theta\right)}$ is needed to guarantee that the first child prefers $\hat{z}$ over even the most favorable allocation in which the second child is born.
} 
are efficient can be a complex question, turning, in part, on somewhat arbitrary choices about how the utility function of the unborn is defined. Intuitively, however, one expects that in normal circumstances, when it is better to be born than not, finding an improving allocation with fewer people alive is not possible. As can be seen however, this depends on the implicit assumption that the unborn do not care about the consumption levels of other family members $(\eta=\lambda=0)$. We consider this formally Section 3.1.3.

\subsubsection{Pareto-efficiency as a special case}

A natural question to ask is whether or not this definition of $\mathcal{P}$-efficiency reduces to the standard one when population is exogenous. That is, given a sequence of planned fertilities, $f_{i}$, for everyone in the economy, Pareto-optimal allocations of consumption goods can be defined in the usual way among those potential agents who are in $I(z)$. In general, a $\mathcal{P}$-efficient allocation will not be Pareto-optimal in this sense without further restrictions on the preferences of the unborn. That is, an alternative consumption plan might improve the welfare of all the agents who are born (i.e., for all $i \in I(z)$ ), but lower the utility of some unborn agent (i.e., some $i \in \mathcal{P} \backslash I(z))$. Because of this, the original allocation would be $\mathcal{P}$-efficient even though it is not Pareto-optimal among the set of born agents. A sufficient condition that this not be the case is that unborn agents are indifferent between all consumption allocations of the born agents. We will denote this utility level by $\bar{u}_{i}$.

Assumption 2 If $i \in \mathcal{P} \backslash I(z) \cap \mathcal{P} \backslash I\left(z^{\prime}\right)$, then $u_{i}(z)=u_{i}\left(z^{\prime}\right)=\bar{u}_{i}$. 
Under this assumption, if an allocation is $\mathcal{P}$-efficient, then the corresponding allocation of consumption goods is Pareto-optimal for the fixed sequence of populations. For completeness, we include this as a Proposition:

Proposition 1 If Assumption 2 holds, and if $\left(z^{*}, y^{*}\right)=\left(\left(x_{i}^{*}, f_{i}^{*}\right)_{i \in P}, y^{*}\right)$ is $\mathcal{P}$-efficient, then the consumption allocation $\left(x^{*}, y^{*}\right)=\left(\left(x_{i}\right)_{i \in I}, y^{*}\right)$ is Paretooptimal among the agents in $I\left(z^{*}\right)$.

\subsubsection{Fewer people can never be $\mathcal{P}$-better}

We return now to the discussion on the possibility of $\mathcal{P}$-ranking alternative populations. As noted, most people when thinking about this problem would, as a first approximation, assume that the unborn do not have preferences. The natural way to model this in our setting is to restrict attention to environments where Assumption 2 holds; that is, the unborn agents are indifferent about the consumption allocation among those agents who are born.

Under this assumption and under the further assumption that the allocation $\left(z^{*}, y^{*}\right)$ does not give any agent $i \in I\left(z^{*}\right)$ a lower level of utility than she has when not born $\left(\bar{u}_{i}\right)$, it follows that no $\mathcal{P}$-superior allocations exist in which $i \in \mathcal{P} \backslash I\left(z^{*}\right)$. Formally, we have the following proposition.

Proposition 2 If preferences satisfy Assumption 2, if the allocation $\left(z^{*}, y^{*}\right)$ satisfies $u_{i}\left(z^{*}\right)>\bar{u}_{i}$ for all $i \in I\left(z^{*}\right)$, and if the allocation $\left(z^{\prime}, y^{\prime}\right)$ is $\mathcal{P}$-Pareto Superior to $\left(z^{*}, y^{*}\right)$, then $I\left(z^{*}\right) \subseteq I\left(z^{\prime}\right)$.

Proof. If not, then there is some $j \in I\left(z^{*}\right) \backslash I\left(z^{\prime}\right)$. Hence, $u_{j}\left(z^{\prime}\right)=\bar{u}_{j}$. But, by assumption, $u_{j}\left(z^{*}\right)>\bar{u}_{j}$ since $j \in I\left(z^{*}\right)$. Thus, $u_{j}\left(z^{\prime}\right)<\bar{u}_{j}<u_{j}\left(z^{*}\right)$, a contradiction. 
The proof of Proposition 2 is straightforward. The key is thus not how to prove it given the assumptions that are made, but rather that assumptions are necessary. ${ }^{7}$ That these assumptions are necessary follows from the examples given above. In particular, in those examples, Assumption 2 implies that people who are not born cannot be altruistic toward their siblings or parents.

The result above shows that there is a sense in which $\mathcal{P}$-efficiency is a very conservative notion. That is, it treats born and unborn agents symmetrically when constructing improving allocations, and because of this fertility cannot be $\mathcal{P}$-inefficiently high (as long as being unborn is the worst outcome).

\subsubsection{A Planner's Problem}

A planner's problem is often used to identify efficient allocations. In standard environments, the equivalence between Pareto-efficient allocations and the solution to maximizing a weighted sum of utilities subject to feasibility can be established under very mild assumptions. A similar result can be obtained in our context, although it is a bit trickier. Below we give a planner's problem and show that the solution to this problem is $\mathcal{P}$-efficient.

Proposition 3 Pick any sequence $\left\{a_{i}\right\}_{i \in \mathcal{P}}$ such that $a_{i}>0 \forall i \in \mathcal{P}$. Suppose $\left(z^{*}, y^{*}\right)$ is a solution to the following problem:

$$
\max _{z, y} \sum_{i \in P} a_{i} u_{i}(z)
$$

\footnotetext{
${ }^{7}$ Note also that if not being born is the best thing in the world, then the opposite conclusion will hold: If $\left(z^{*}, y^{*}\right)$ satisfies $\bar{u}_{i}>u_{i}(z) \forall i \in P \backslash I\left(z^{*}\right)$ and $\forall z \in Z$ and if $\left(z^{\prime}, y^{\prime}\right)$ is superior to $\left(z^{*}, y^{*}\right)$, then $I\left(z^{*}\right) \supseteq I\left(z^{\prime}\right)$.
} 
subject to feasibility and suppose that $\sum_{i \in P} a_{i} u_{i}\left(z^{*}\right)<\infty$. Then $\left(z^{*}, y^{*}\right)$ is $\mathcal{P}$-efficient.

Proof. Suppose not. Then a exist a feasible allocation, $(\hat{z}, \hat{y})$ and a $j \in$ $\mathcal{P}$ such that $u_{j}(\hat{z})>u_{j}\left(z^{*}\right)$ and $u_{i}(\hat{z}) \geq u_{i}\left(z^{*}\right) \quad \forall i \in \mathcal{P}$. But then (and here the finiteness assumption is crucial) $\sum_{i \in \mathcal{P}} a_{i} u_{i}(\hat{z})>\sum_{i \in \mathcal{P}} a_{i} u_{i}\left(z^{*}\right)$, a contradiction.

Note that the reverse is not necessarily true.

\subsubsection{Existence}

Is the proposed efficiency concept welldefined? Specifically, are there situations in which it does not exist? Under fairly weak conditions, the set of $\mathcal{P}$-efficient allocations is nonempty, as can be seen in the next proposition.

Proposition 4 Assume utility functions are continuous and uniformly bounded above and below, that $\hat{Z} \subset \mathbb{R}^{k} \times \mathcal{F}$ is closed, that $Y \subset \mathbb{R}^{k \infty}$ is closed in the product topology, and that the set of feasible allocations is bounded period by period. Then the set of $\mathcal{P}$-efficient allocations is nonempty.

Proof. Pick $0<\delta<1$. Then define $a_{i t}=\frac{\delta^{t}}{\left|\mathcal{P}_{t}\right|}$ for $i \in \mathcal{P}_{t}$, where $\left|\mathcal{P}_{t}\right|$ denotes the number of elements in $\mathcal{P}_{t}$. Now consider the following maximization problem

$$
\begin{aligned}
& \max _{z, y} \sum_{t=0}^{\infty} \sum_{i \in \mathcal{P}_{t}} a_{i t} u_{i}(z) \text { s.t. } \\
& z_{i} \in Z_{i}\left(z_{-i}\right) \forall i \\
& \sum_{i \in \mathcal{P}_{t}} x_{i}+\sum_{i \in \mathcal{P}_{t}} c\left(f_{i}\right)=\sum_{i \in \mathcal{P}_{t}} e_{i}+y_{t} \forall t .
\end{aligned}
$$


The arguments in Jones and Manuelli (1990) can be used to show that the objective function in this problem is continuous in the product topology. It follows from our assumptions that the set of allocations that are feasible is closed in the product topology. By assumption, the feasible set is bounded, and hence, it follows that it is compact in the product topology. Therefore, a maximum exists. Since utility functions are uniformly bounded, the weights as chosen guarantee convergence of the infinite sum. Hence, we can use Proposition 3 to conclude that such a maximizer is $\mathcal{P}$-efficient.

The assumption that utility is uniformly bounded is stronger than is necessary. Jones and Manuelli (1990) and Alvarez and Stokey (1998) show how this can be relaxed for special cases. Similarly, the assumption that the set of feasible allocations is bounded can be built up from assumptions at the individual level. (See Bewley (1972).)

\section{$3.2 \mathcal{A}$-efficiency}

This section describes the second efficiency concept. It is a natural modification of $\mathcal{P}$-efficiency, which treats born and not born potential people asymmetrically.

Definition 3 A feasible allocation $(z, y)=\left(\left\{\left(x_{i}, f_{i}\right)\right\}_{i \in P}, y\right)$ is $\mathcal{A}$-efficient if there is no other feasible allocation $(\hat{z}, \hat{y})$ such that

1. $u_{i}\left(\hat{x}_{i}, \hat{f}_{i}, \hat{z}_{-i}\right) \geq u_{i}\left(x_{i}, f_{i}, z_{-i}\right) \quad \forall i \in I(z) \cap I(\hat{z})$

2. $u_{i}\left(\hat{x}_{i}, \hat{f}_{i}, \hat{z}_{-i}\right)>u_{i}\left(x_{i}, f_{i}, z_{-i}\right)$ for some $i \in I(z) \cap I(\hat{z})$ 
This definition differs from $\mathcal{P}$-efficiency in that only a subset of the potential population is considered when making utility comparisons across allocations. An allocation is superior if no one who is alive in both allocation is worse off and at least one person alive under both allocations is strictly better off. Since utility comparisons are made only for the agents who are in fact born, (i.e., $i \in I(z) \cap I(\hat{z}))$ it has the added advantage of not requiring utility functions to be defined for agents who are not born. We call it $\mathcal{A}$-efficiency because only 'alive' agents are considered.

\subsubsection{The Relationship between $\mathcal{A}$ - and $\mathcal{P}$-efficiency.}

Intuitively, one expects the set of $\mathcal{A}$-efficient allocations to be a subset of the set of $\mathcal{P}$-efficient allocations since it is easier to find a superior allocation. Since utility improvements are not required under $\mathcal{A}$-efficient allocations for those agents not born in a candidate blocking allocation, in the typical case, the set of $\mathcal{A}$-efficient allocations consists of those $\mathcal{P}$-efficient allocations for which no parent can be made better off by decreasing fertility. While this is true for most examples, consider the following counterexample. One initial parent has two potential children. Childrearing has no costs. Both the parent and the first child have an endowment of one if born, while the second child has no endowment. Utility functions for the parent and the first child are $u_{i}\left(c_{i}\right)=c_{i}$, whereas the second child if born is altruistic toward his sibling $u_{(1,2)}=f_{2}\left[\ln \left(1+c_{3}\right)+u_{(1,1)}\right]$. Consider the allocation

$$
z=\left\{c_{1}=1, f_{1}=1, f_{2}=0, c_{(1,1)}=1, c_{(1,2)}=0\right\}
$$


This allocation is $\mathcal{A}$-efficient, since no other allocation makes any alive person strictly better off. Yet it is not $\mathcal{P}$-efficient, as it is dominated by the following allocation:

$$
\hat{z}=\left\{c_{1}=1, f_{1}=1, f_{2}=1, c_{(1,1)}=1, c_{(1,2)}=0\right\}
$$

The second child strictly prefers being born and not consuming anything over not being born; therefore, $z$ is not $\mathcal{P}$-efficient.

Examples like the above are rare and do not seem very robust. They are related to the fact that in our setting, two alternative definitions of Paretooptimality are not equivalent. Consider a slight variation of $\mathcal{P}$-efficiency:

Definition 4 A feasible allocation $(z, y)=\left(\left\{\left(x_{i}, f_{i}\right)\right\}_{i \in P}, y\right)$ is $\mathcal{P}^{\prime}$-efficient if there is no other feasible allocation $(\hat{z}, \hat{y})$ such that $u_{i}\left(\hat{x}_{i}, \hat{f}_{i}, \hat{z}_{-i}\right)>u_{i}\left(x_{i}, f_{i}, z_{-i}\right)$ for all $i \in \mathcal{P}$

The analog of this concept for exogenous fertility models is called weak Pareto-efficiency, and under mild assumptions, it is equivalent to the usual notion of Pareto-efficiency. Focusing on environments in which the same is true here (i.e., environments such that the set of $\mathcal{P}$-efficient allocations coincides with the set of $\mathcal{P}^{\prime}$-efficient allocations), also rules out examples like the one given. If an allocation is superior only when it benefits everyone in $\mathcal{P}$ strictly, then obviously it also benefits everyone alive strictly. Hence, in such environments, the set of $\mathcal{A}$-efficient allocations is a subset of the set of $\mathcal{P}$-efficient allocations.

Examples of allocations that are $\mathcal{P}$-efficient and not $\mathcal{A}$-efficient are more common because a superior allocation that needs to benefit only a subset of the population and allows everyone else to be ignored is simpler to find. This 
means that in many environments, we expect the set of $\mathcal{A}$-efficient allocations to be considerably smaller than the set of $\mathcal{P}$-efficient allocations. The fact that counterexamples to this general proposition exist seems to be related to the indivisibility of fertility choice and the potential utility jump a person can experience when going from being unborn to being born. If it was possible to be half-born (or $\epsilon$-born), and if utility was continuous in the degree of being born, then we suspect that an allocation that is superior in the $\mathcal{A}$-sense would also be superior in the $\mathcal{P}$-sense. This would then imply that $\mathcal{A}$-efficiency would be a subset of $\mathcal{P}$-efficiency.

\subsubsection{Existence}

There is a slight problem with $\mathcal{A}$-efficiency - $\mathcal{A}$-efficient allocations may not exist. Examples exist in which cycles occur and then no allocation is $\mathcal{A}$ efficient. These situations are rare, however. For example, any allocation that maximizes a linear combination of the utilities of the agents alive in period 0 is $\mathcal{A}$-efficient as long as this maximizer is unique (for given weights). Typically, uniqueness would be guaranteed by assuming enough concavity on utility functions. Here, because of the indivisibilities in fertility choice, there is no natural way to guarantee this.

\subsection{Sequential $\mathcal{P}$-Efficiency}

This section briefly describes a refinement of $\mathcal{P}$-efficiency that we call sequential $\mathcal{P}$-efficiency. The refinement proceeds sequentially - we first make generation 0 as happy as possible. Then, having children is only efficient insofar as it 
benefits generation 0 (either directly by providing utility or indirectly by providing labor, etc.). If a parent is indifferent between having a child and not, only then is the welfare of the children taken into consideration. Similarly, for later generations, fertility in period $t$ is only efficient if it does not make anyone from a previous generation worse off. Formally, we have the following definition.

Definition 5 A feasible allocation $(z, y)$ is sequentially $\mathcal{P}$-efficient if $\forall T \nexists(\hat{z}, \hat{y})$ such that

1. $(\hat{z}, \hat{y})$ is feasible

2. $u_{i}(\hat{z}) \geq u_{i}(z) \forall i \in \bigcup_{t \leq T} \mathcal{P}_{t}$

3. $u_{i}(\hat{z})>u_{i}(z)$ for some $i \in \mathcal{P}_{T}$.

This concept is similar in spirit to $\mathcal{A}$-efficiency because it also introduces an asymmetry between people who are alive and those who are not alive. But in addition, it introduces an asymmetry between generations. In this sense the concept has more the flavor of a welfare criterion than an efficiency concept. In particular, when fertility is exogenous, this concept will typically give a much smaller set than the set of Pareto-efficient allocations because the concept is heavily biased towards the initial generation. Later generations count only inasmuch as earlier generations are indifferent. However, sequential $\mathcal{P}$-efficiency has two nice features: it is a strict subset of $\mathcal{P}$-efficiency, and it always exists. The proofs are omitted here, but are available upon request. 


\section{Cooperation Within the Family and the First Welfare Theorem}

Our economy has external effects both in utility and in consumption sets, of a very limited type. In particular, by construction, the only agents in the economy who can affect $i$ 's consumption set are individual agents who are in $i$ 's family, but were born before agent $i$. Moreover, in our description of the consumption sets, these agents can only affect $i$ 's choice set through their fertility decisions. In keeping with this structure, in this section we examine the validity of the first welfare theorem under the assumption that within a family (but not across families) individual agents are cooperative. That is, we formulate a notion of dynastic maximization that corresponds to a Pareto criterion within the dynasty.

We show that as long as all external effects are confined within the family, families view themselves as not affecting prices and, within the family, decision making satisfies this notion of cooperation, then fertility choices are efficient. In the next section, we address the question: Under what conditions do noncooperative formulations of the dynastic decision problem lead to cooperative dynastic decisions in the sense required here.

Assumption 3 We assume that $u_{i}$ is monotone increasing in $x_{j}$, that is each agent is weakly better off when any other agent's consumption is increased. Thus, there are no negative external effects in consumption.

Definition 6 A Dynastic Structure, $\mathcal{D}$, is a partition of the population. That is, $\mathcal{P}=\cup_{\tau} D_{\tau}$, where $D_{\tau} \cap D_{\nu}=\emptyset$ if $\tau \neq \nu$, and for all $D_{\tau} \in \mathcal{D}, D_{\tau} \neq \emptyset$. A 
Dynasty is a member of this partition, $D_{\tau}$.

Assumption 4 We assume that if $z$ and $z^{\prime}$ are two allocations such that $z_{i}=$ $z_{i}^{\prime}$ for all $i \in D_{\tau}$, then $u_{j}(z)=u_{j}\left(z^{\prime}\right)$ and $Z_{j}(z)=Z_{j}\left(z^{\prime}\right)$ for all $j \in D_{\tau}$. Thus, those positive external effects that do exist are confined to a dynasty.

The idea behind a dynastic structure is to isolate the totality of external effects within an associated group. For models with endogenous fertility, the external effects are typically limited to the dynasty that an agent belongs to. Thus, by assumption, agents $i$ and $j$ must necessarily belong to the same dynasty if $i^{t-k}=j$ for some $k$, meaning that $j$ is a predecessor of $i$. It also follows that all agents with a common predecessor must be in the same dynasty (since a dynastic structure is a partition, and they must both be in the same dynasty as their common ancestor). It follows that under the maintained assumptions, there are at most $N$ dynasties in a given economy, each corresponding to a different period 0 agent.

We suspect that this separation between agent groups that are externality linked is likely to be useful more generally, however.

Next, we define what it means for an allocation to be optimal for a given dynasty at a given price sequence. Intuitively, an allocation is dynastically maximizing if and only if there is no way of increasing the utility of every member of the dynasty without increasing overall spending by the dynasty.

Before defining a notion of family optimization, we need to specify an ownership structure for the firm. To simplify, we will assume the firm is owned only by members of the initial generation. So let $\psi_{i}$ specify the fraction of the firm that belongs to $i, i \in \mathcal{P}_{0}$. For a well-defined ownership structure, 
we need $\psi_{i} \geq 0$, and $\sum_{i \in \mathcal{P}_{0}} \psi_{i}=1$.

Definition 7 Given $\left(p, y, z_{-\tau}\right)$, a dynastic allocation $z_{\tau}=\left\{z_{i}\right\}_{i \in D_{\tau}} \in Z_{\tau}$ is said to be Dynastically $\mathcal{P}$-maximizing if $\nexists \hat{z}=\left(\hat{z}_{\tau}, z_{-\tau}\right)$ such that:

1. $\hat{z}_{i} \in Z_{i}\left(\hat{z}_{-i}\right)$ for all $i \in D_{\tau}$.

2. $u_{i}\left(\hat{z}_{i}, \hat{z}_{-i}\right) \geq u_{i}\left(z_{i}, z_{-i}\right)$ for all $i \in D_{\tau}$.

3. $u_{i}\left(\hat{z}_{i}, \hat{z}_{-i}\right)>u_{i}\left(z_{i}, z_{-i}\right)$ for at least one $i \in D_{\tau}$.

4. $\sum_{t} p_{t} \sum_{i \in D_{\tau} \cap \mathcal{P}_{t}}\left(\hat{x}_{i}+c\left(\hat{f}_{i}\right)\right) \leq \sum_{i \in D_{\tau} \cap \mathcal{P}_{t}} p_{t} e_{i}+\sum_{i \in \mathcal{P}_{0} \cap D_{\tau}} \psi_{i} \sum_{t} p_{t} y_{t}$.

For notational simplicity in what follows, we will use $\Pi_{\tau}$ to denote a dynasty's profits earned; that is, $\Pi_{\tau}=\sum_{i \in \mathcal{P}_{0} \cap D_{\tau}} \psi_{i} \sum_{t} p_{t} y_{t}$. Note that this depends on both prices and the production plan of the firm.

An allocation being dynastically maximizing corresponds naturally to the dynasty overall using maximizing behavior given the resources it has available to it overall. Note that since there is only one, dynastic, budget set, it is as if the dynasty is fully free to make any transfers of wealth inside the dynasty that it chooses. Thus, an allocation being dynastically maximizing implies that are no further transfers within the dynasty can improve dynastic welfare (in a Pareto sense). Finally, for those agents in the dynasty who are not born, feasibility requires that $\hat{x}_{i}=e_{i}$ and $\hat{f}_{i}=0$, and hence, they drop out of the dynastic budget constraint entirely.

Next we define the analog of a competitive equilibrium among the dynasties in the partition.

Definition $8\left(p^{*}, z^{*}, y^{*}\right)$ is a dynastic $\mathcal{P}$-equilibrium if 
1. For all dynasties, given $\left(p^{*}, y^{*}, z_{-\tau}^{*}\right), z_{\tau}^{*}$ is dynastically $\mathcal{P}$-maximizing.

2. $\left(z^{*}, y^{*}\right)$ is feasible.

3. Given $p^{*}, y^{*}$ maximizes profits, i.e. $p^{*} y \leq p^{*} y^{*}, \quad \forall y \in Y$.

Lemma 1 Assume dynasty $D_{\tau}$ has at least one member alive at time 0 with strictly monotone preferences. Let $z_{\tau}^{*}$ be dynastically $\mathcal{P}$-maximizing for dynasty $D_{\tau}$, given prices $p$ and production $y$. Then $u_{i}\left(z_{\tau}, z_{-\tau}^{*}\right) \geq u_{i}\left(z_{\tau}^{*}, z_{-\tau}^{*}\right)$ for all $i \in D_{\tau}$ implies that $\sum_{t} p_{t} \sum_{i \in D_{\tau} \cap \mathcal{P}_{t}}\left(x_{i}+c\left(f_{i}\right)\right) \geq \Pi_{\tau}+\sum_{t} p_{t} \sum_{i \in D_{\tau} \cap \mathcal{P}_{t}} e_{i}$.

Proof. This will be proved by contradiction. Suppose not. Then there exists a $z_{\tau}$ such that $u_{i}\left(z_{\tau}, z_{-\tau}^{*}\right) \geq u_{i}\left(z^{*}\right)$ for all $i \in D_{\tau}$ and $\sum_{t} p_{t} \sum_{i \in D_{\tau} \cap \mathcal{P}_{t}}\left(x_{i}+\right.$ $\left.c\left(f_{i}\right)\right)<\Pi_{\tau}+\sum_{t} p_{t} \sum_{i \in D_{\tau} \cap \mathcal{P}_{t}} e_{i}$. Let $j \in D_{\tau} \cap \mathcal{P}_{0}$ have strictly monotone preferences. Then construct $\tilde{z}$ as follows: $\tilde{z}_{i}=z_{i} \forall i \neq j$ and $\tilde{z}_{j}=\left(z_{j}+\epsilon, f_{j}\right)$. Then $\exists \epsilon>0$ such that the dynastic allocation $\tilde{z}_{\tau}$ does not violate the dynastic budget constraint. Moreover, by Assumption 3, $z$ is weakly preferred over $z$ by all $i$ in the dynasty and hence also over $z^{*}$. Finally, by strict monotonicity, $u_{j}(\tilde{z})>u_{j}\left(z^{*}\right)$. But this contradicts the assumption that $z_{\tau}^{*}$ is dynastically $\mathcal{P}$-maximizing.

Proposition 5 Suppose $u_{i}\left(x_{i}, f_{i}, z_{-i}\right)$ is strictly monotone in $x_{i}$ for all $i \in \mathcal{P}_{0}$. If $\left(p^{*}, z^{*}, y^{*}\right)$ is a dynastic $\mathcal{P}$-equilibrium, then $\sum_{t} p_{t}\left(\sum_{i \in \mathcal{P}_{t}} e_{i}+y_{t}^{*}\right)<\infty$, and $\left(z^{*}, y^{*}\right)$ is $\mathcal{P}$-efficient.

Proof. First, note that since $u_{i}\left(x_{i}, f_{i}, z_{-i}\right)$ is strictly monotone in $x_{i}$ for all $i \in \mathcal{P}_{0}$, for the given allocation to be a dynastic $\mathcal{P}$-equilibrium, $z_{i}$ must be dynastically $\mathcal{P}$-maximizing, and hence, 


$$
\Pi_{\tau}+\sum_{t} \sum_{i \in \mathcal{P}_{t}} p_{t} e_{i}<\infty, \text { for all } \tau \text {. }
$$

Summing over $\tau$ gives

$$
\sum_{t} p_{t}\left(\sum_{i \in \mathcal{P}_{t}} e_{i}+y_{t}^{*}\right)<\infty .
$$

Now $\left(z^{*}, y^{*}, p^{*}\right)$ is a dynastic $\mathcal{P}$-equilibrium and by way of contradiction, assume that it is not $\mathcal{P}$-efficient. Then an alternative feasible allocation $(z, y)$, exists that is $\mathcal{P}$-superior to $\left(z^{*}, y^{*}\right)$. That is, $u_{i}(z) \geq u_{i}\left(z^{*}\right)$ for all $i \in \mathcal{P}$ and $u_{i}(z)>u_{i}\left(z^{*}\right)$ for at least one $i \in P$. Without loss of generality, assume $i \in D_{\tau}$. Then, since $z_{\tau}^{*}$ is dynastically $\mathcal{P}$-maximizing, and since there are no external effects across dynasties (Assumption 4), for dynasty $D_{\tau}$, it must be that $z_{\tau}$ was not affordable, i.e.

$$
\sum_{t} p_{t}^{*} \sum_{i \in D_{\tau} \cap \mathcal{P}_{t}}\left(x_{i}+c\left(f_{i}\right)\right)>\Pi_{\tau}+\sum_{t} p_{t}^{*} \sum_{i \in D_{\tau} \cap \mathcal{P}_{t}} e_{i}
$$

Moreover, by Lemma 1, we know that for all other dynasties, the following must hold:

$$
\sum_{t} p_{t}^{*} \sum_{i \in D_{\tau} \cap \mathcal{P}_{t}}\left(x_{i}+c\left(f_{i}\right)\right) \geq \Pi_{\tau}+\sum_{t} p_{t}^{*} \sum_{i \in D_{\tau} \cap \mathcal{P}_{t}} e_{i}
$$

Summing over all dynasties, we get

$$
\sum_{t} p_{t}^{*} \sum_{i \cap \mathcal{P}_{t}}\left(x_{i}+c\left(f_{i}\right)\right)>\sum_{t} p_{t}^{*}\left[y_{t}^{*}+\sum_{i \cap \mathcal{P}_{t}} e_{i}\right]
$$

Note that the right hand side is finite; hence, the strict inequality is preserved. Profit maximization implies that $p^{*} y^{*} \geq p^{*} y$ for all other production plans $y \in Y$. Using this, we can rewrite equation 2 as

$$
\sum_{t} p_{t}^{*} \sum_{i \cap \mathcal{P}_{t}}\left(x_{i}+c\left(f_{i}\right)\right)>\sum_{t} p_{t}^{*}\left[y_{t}+\sum_{i \cap \mathcal{P}_{t}} e_{i}\right]
$$

Finally, feasibility of $(x, y)$ implies that

$$
\sum_{i \in \mathcal{P}_{t}}\left(x_{i}+c\left(f_{i}\right)\right) \leq y_{t}+\sum_{i \in \mathcal{P}_{t}} e_{i} \text { for all } t
$$


Multiplying the above by $p_{t}^{*}$ and summing over $t$ gives

$$
\sum_{t} p_{t}^{*} \sum_{i \in \mathcal{P}_{t}}\left(x_{i}+c\left(f_{i}\right)\right) \leq \sum_{t} p_{t}^{*}\left[y_{t}+\sum_{i \in \mathcal{P}_{t}} e_{i}\right]
$$

But this contradicts equation 3. This completes the proof.

Summarizing the results from this section, we see that as long as each dynasty solves the internal redistribution problem efficiently, there are no external effects across dynasties, and all dynasties take prices as given, dynastic equilibria are efficient. In particular, fertility choices are efficient.

An analog of the first welfare theorem holds for $\mathcal{A}$-efficiency as well as for sequential $\mathcal{P}$-efficiency. The propositions and proofs are very similar to the above and are hence omitted here.

\section{Dynastic Games and Efficiency}

As is standard in models with external effects, equilibrium will naturally involve a mixture of price-taking behavior and quantity-taking behavior - the agent takes the prices it faces as fixed, and takes the actions, in particular the fertility choices of the other agents as fixed, when making its own consumption and fertility choices. Thus, the equilibrium notion is a mixture of Nash and Walrasian equilibrium.

Exactly what this means depends on the nature of the game being played by the agents, of course. The most straightforward treatment would be to formulate a game in which agents' choices are simultaneous moves chosen at time zero. One would then formulate the game in which the action of each agent included not only his own consumption and fertility choices, but 
also, possibly, a complex scheme of transfers to the other agents in his own dynasty. This game would generate a set of equilibrium strategy profiles, each of these generating an equilibrium outcome in terms of consumption and fertility decisions. Given the development in the sections above, the question would be, What types of games would generate equilibrium outcomes that are dynastically efficient (in either the $\mathcal{P}$, the $\mathcal{A}$ or the sequential $\mathcal{P}$ sense)?

Since fertility is intrinsically a dynamic decision, however, this is not the typical way (or the best way) to model these types of decisions. Rather, models of fertility usually have a dynamic game theoretic formulation in which each agent who is born in period $t$ must choose levels of both consumption and fertility in period $t+1$ as a function of all previous actions chosen by the preceding agents in his dynasty. These actions involve both the consumption and the fertility decisions of predecessors as well as the bequests left, etc.

Further, we want to think of external effects as arising only within a dynasty, and we want to preserve the notion that each dynasty is small relative to the aggregate. Because of this, we will assume that each dynasty views itself as having no effects on prices.

Finally, since these games are dynamic in form, the issue of equilibrium refinements arises quite naturally. Minimally, we will assume subgame perfection. Typically, we will use something stronger, focusing only on those subgame perfect equilibria of the supergame that are the limits of subgame perfect equilibria of finite horizon versions of the dynastic game.

We think of each dynasty as being small and so they take prices for goods $\left\{p_{t}\right\}$ as given. Given prices, each member of every dynasty chooses actions $a_{t}$ from the action set $A_{t}\left(\left\{p_{t}\right\}, a^{t-1}\right)$, where $a^{t-1}$ is the history of actions taken 
before she was born. These actions will typically include, at a minimum, fertility decisions, choices of consumption, and bequests. The action set depends on the equilibrium prices and actions taken by the previous generations. Thus, if an agent's parents decided that she will not be born, her action set will be the singelton $\left\{e_{t}\right\}$. Thus, formally, each agent has a strategy space $S_{t}\left(\left\{p_{t}\right\}, h^{t}\right)$ which depends on both equilibrium prices and the history of actions to that date. The strategies $s_{t} \in S_{t}$ are chosen to maximize individual utility $u\left(s_{i}, s_{-i}\right)$. Finally, the prices are such that markets clear,

$$
\sum_{i \in \mathcal{P}_{t}} x_{i}+\sum_{i \in \mathcal{P}_{t}} c\left(f_{i}\right)=\sum_{i \in \mathcal{P}_{t}} e_{i}+y_{t} \text { for all } t .
$$

In context, then, the definitions and propositions stated above properly concern the equilibrium outcomes (i.e., the actions along the equilibrium path) of this dynamic formulation of the choice problems. At this level of generality of the problem and the types of external effects we allow, one can easily construct examples in which the equilibrium outcomes will not be efficient. What is perhaps surprising is that natural examples exist in which this is not true. That is, the equilibrium outcomes of this dynamic game are efficient $(\mathcal{P}, \mathcal{A}$, and sequential $\mathcal{P})$.

Throughout this section, we will confine our attention to conditions under which the equilibrium outcome of the game played within the dynasty, for given prices, is dynastically maximizing. Given the results of the preceding section, it follows that if this is true for all dynasties at the equilibrium prices, the resulting equilibrium allocation is efficient as well.

The remainder of this section consists of three parts. Sections 5.1 and 5.2 identify sufficient conditions for the equilibrium of the dynasty game to be efficient. We find that the degree of altruism and the richness of contracts 
between ancestors and descendants are crucial ingredients. We analyze two extreme cases. In the first case, dynasties are perfectly altruistic. This includes the Barro-Becker model as a special case. The altruism eliminates the time inconsistency problem between parents and their descendants. Due to agreement between parents and children, contracts between parents and children can be fairly limited. We find that in this case, allowing for period-by-period bequests to a parents' own children is sufficient for efficiency. These bequests may need to be negative in some cases if the dynasties are sufficiently different. ${ }^{8}$

The second extreme puts no restrictions on preferences, but requires a rich set of bequest contracts. In particular, we show that if the head of the dynasty has a rich set of transfers that allows him to dictate the behavior of all descendants, then the time inconsistency problem becomes irrelevant. This is a very extreme case, obviously. The point we want to emphasize here is that some combination of altruism and richness in bequests is needed to ensure that the equilibrium outcome of the game is efficient.

The last section gives some examples of inefficient equilibrium outcomes. The examples illustrate what can cause intra-family decisions to be inefficient. The first example emphasizes that solutions to intra-generational dynamic games can be inefficient if bequests are not allowed to be negative. We then

\footnotetext{
${ }^{8}$ ¿From a formal point of view, this problem is similar to that studied in the clubs literature: When does a noncooperative formulation give rise to efficient outcomes? (See Scotchmer (1997) for an example.) However, the mechanism at work here is quite different. In club and other local public good environments, efficiency is guaranteed by competition between the clubs for members. Here, since the dynasty is the analog of a club, no such competition between clubs is possible. Rather, here the natural alignment of incentives within a family guarantees efficiency within the group.
} 
show that allowing negative bequests may still not be enough to solve the time inconsistency problem between parents and children. The section concludes with an example demonstrating that not every time inconsistency has to lead to an inefficiency.

\subsection{The Barro-Becker Model}

One of the principle economic models of fertility is pioneered in Becker and Barro (1988) and Barro and Becker (1989). In this section, we show how our approach to efficient fertility can be applied to that class of models. In that approach, at each date, $t$, the individuals alive make decisions about their own consumption, how many children to have, and how large a bequest to leave each child. To make the model more tractable, Barro and Becker assume that fertility can take on any positive value, not just integers. Because of this, the analysis of the preceding sections do not directly apply to the Barro-Becker model. The modifications necessary are straightforward, however. ${ }^{9}$

We generalize the Barro-Becker framework here by allowing for more than one period 0 person. Each initial agent is the dynastic head of his own dynasty. We allow dynasties to differ in their initial capital stock $k_{0}^{\tau}$, child-rearing costs $\theta_{t}^{\tau}$, discount factor $\beta^{\tau}$, and skill $a_{t}^{\tau}$. Let $w_{t}$ be the wage per skill unit at time $t$ and $r_{t}$ the return on capital. We also use a more general utility function. For most parts in this section, it is enough to focus on one dynasty. For these cases we drop the superscript $\tau$.

In the Barro-Becker model, it is assumed that each agent alive in period $t$,

\footnotetext{
${ }^{9}$ Details on this are available online in the appendix to this paper. See Golosov, Jones and Tertilt (2003) at http://www.econ.umn.edu/ lej/lejresearch.html.
} 
$i^{t}$, must choose his current consumption level, $x_{t}\left(i^{t}\right)$, his fertility level, $f_{t}\left(i^{t}\right) \in$ $[0, \bar{f}]$ and a bequest level for each of his children, subject to his own budget constraint:

$$
p_{t} x_{t}\left(i^{t}\right)+c\left(f_{t}\left(i^{t}\right)\right)+\int_{0}^{f_{t}\left(i^{t}\right)} b_{i^{t}}\left(i_{t+1}\right) d i_{t+1} \leq p_{t} e_{t}\left(i^{t}\right)+b_{i^{t-1}}\left(i_{t}\right)
$$

Note that this includes the bequest that he has received from his own parents, $b_{i^{t-1}}\left(i_{t}\right)$. It is assumed that his preferences are given recursively by:

$$
U_{t}\left(i^{t}\right)=u\left(x_{t}\left(i^{t}\right)\right)+\beta g\left(f_{t}\left(i^{t}\right)\right) \int_{0}^{f_{t}\left(i^{t}\right)} U_{t+1}\left(i^{t+1}\right) d i_{t+1} .
$$

Each agent in each dynasty views the entire sequence of prices as given when making this choice.

Since our goal is to establish that an equilibrium is sequentially $\mathcal{P}$-efficient, when prices are determined by the interaction of multiple price-taking dynasties, we must first have a precise definition of what the equilibrium is. To do this, we will model the formulation above as an infinite horizon game in which each period each child that is born must make decisions as given above. How then does a time $t$ decision maker conjecture the future utility of his children? Of course, the answer is that they must correspond to the actual utility levels that these children receive if they optimally respond to the bequests that they receive from their parents, etc. That is, the sequence of consumption, fertility, bequest plans should be a subgame perfect equilibrium (SPE) of this infinite horizon game. Of course, there are typically many SPE's of infinite horizon games involving different threats of punishments off the equilibrium path. There is no easy way to select among these different equilibria, but one common selection criterion is that it not be too dependent on the assumption 
that time lasts forever. That is, it should be the limit of the equilibria of the finite horizon truncations of the infinite horizon game. This is the criterion that we will use below. Formally, our definition of equilibrium is:

Definition 9 An equilibrium is prices $\left\{p_{t}\right\}$ and $\left\{x_{t}^{\tau}(i), f_{t}^{\tau}(i)\right\}_{t, i}$ for each $d y$ nasty $\tau$ such that:

1. For each dynasty $\tau,\left\{x_{t}^{\tau}(i), f_{t}^{\tau}(i)\right\}_{t, i}$ is the limit of the subgame perfect equilibrium outcome of the finite dynasty game.

2. The allocation is feasible.

To prove that the Barro-Becker equilibrium is sequentially $\mathcal{P}$-efficient, we need to show that all dynasties are sequentially $\mathcal{P}$-maximizing in the dynastic Barro-Becker game. The details for this proof are available in Golosov, Jones and Tertilt (2003), where a $T$ period truncation of the infinite horizon game is defined. It is then shown that the subgame perfect equilibrium outcome of this game coincides with the dynastic head choosing his most preferred outcome and moreover, that this is unique. This result depends on the following four assumptions:

Assumption $5 u(\cdot)$ is continuous, strictly increasing, strictly concave and $u(0)=0$.

Assumption $6 c(f)=\theta f$.

Assumption 6 implies that $f_{1} c\left(f_{2}\right)=c\left(f_{1} f_{2}\right)$, which will be used below.

Assumption $7 g(\cdot)$ satisfies $g(x) g(y)=g(x y)$. 
Assumption $8 H(F, X) \equiv g(F) F u(X / F)$ is strictly concave in $(F, X)$.

Then we have the following:

Proposition 6 Let the allocation $z=\left\{z^{\tau}\right\}_{\tau}$, where $z^{\tau}=\left(c_{t}^{\tau}, f_{t}^{\tau}, k_{t+1}^{\tau}\right)_{t}$, together with prices $\left\{w_{t}, r_{t}\right\}$ be a Barro-Becker equilibrium as defined in Definition 9. Then under Assumptions 5-8, along the equilibrium path, all dynasties are dynastically sequentially $\mathcal{P}$-maximizing given prices.

Given this result, we can then state the main result of this section:

Theorem 1 Let the allocation $z=\left\{z^{\tau}\right\}_{\tau}$, where $z^{\tau}=\left(c_{t}^{\tau}, f_{t}^{\tau}, k_{t+1}^{\tau}\right)_{t}$, together with prices $\left\{w_{t}, r_{t}\right\}$ be a Barro-Becker equilibrium as defined in Definition 9. Then under Assumptions 5-8, z is sequentially $\mathcal{P}$-efficient.

Proof. This follows immediately from the first welfare theorem (for sequentially $\mathcal{P}$-maximizing dynasties) together with Proposition 6 above: $z^{\tau}$ is sequentially $\mathcal{P}$-maximizing for each dynasty $\tau$ by Proposition 6 ; it is also feasible, since it is an equilibrium. There are no externalities across dynasties by assumption; hence it must be sequentially $\mathcal{P}$-efficient.

Note that an immediate corollary to Theorem 1 is that the equilibrium allocation is also $\mathcal{P}$-efficient. This follows from the fact that the set of sequentially $\mathcal{P}$-efficient allocations is a strict subset of the set of $\mathcal{P}$-efficient allocations. That it is also $\mathcal{A}$-efficient follows from the fact that, for each dynasty, the equilibrium allocation is the unique maximizer of the utility function of the dynasty head at the equilibrium prices.

In the above we have assumed that it is feasible for parents to leave negative bequests to their children. We would like to know if this is a necessary 
assumption. Assume that there is a nonnegativity constraint on bequests, $k_{t}^{\tau} \geq 0$. Note that if all dynasties were identical, then this constraint would never be binding in equilibrium; and hence, the equilibrium allocation would still be (sequentially) $\mathcal{P}$-efficient. If dynasties are heterogeneous, but not too different, then the same logic will still apply by continuity. However, if the heterogeneity is big, then prohibiting negative bequests can indeed lead to an inefficiency in the Barro-Becker environment, as we will see in Section 5.3.

\subsection{Dynastic Dictators}

In this section, we again model the rate of growth of population as the equilibrium outcome of a game played within a dynasty, but deviate from the assumption that preferences are perfectly time consistent. Without this assumption something extra must be added to guarantee that, given prices, the outcome within the family is dynastically maximizing. Our strategy is to allow for virtually any type of preferences but to also allow a rich set of bequest contracts for the dynastic head to choose from. This allows the initial generation to force its most preferred outcome even if this is not what the subsequent generations would choose if left on their own.

In a sense, this result, which is fairly intuitive, is at the opposite extreme from the one given in section 5.1. Taken together, they imply that if the head has a sufficiently rich set of transfers which he can use to manipulate bequests, the family equilibrium outcome will be dynastically maximizing. The richness needed to insure this depends, quite naturally, on the extent of time consistency problems within the family. 
We will confine our attention to a single dynasty, $\tau$, and will assume that this dynasty has only a single member at time 0 .

Consider an infinite horizon game with $t$ running from 0 on. In period 0 , the head chooses his own consumption, $x_{0}$, his own fertility, $f_{0}$, and his bequests, $b^{0}$. We will allow for $b^{0}$ to be fully dependent on the consumption and fertility decisions of his descendents. That is, $b^{0}$ is a family of realvalued functions indexed by $i^{t}, t=0,1, \ldots, i=1, \ldots, \bar{f}, b^{0}\left(\cdot ; i^{t}\right)$, with domain given by $\eta^{t}=\left(x_{0}, f_{0}, x_{1}(1), f_{1}(1), b_{1}(1,1), \ldots, x_{1}(\bar{f}), f_{1}(\bar{f}), b_{1}(\bar{f}, 1), \ldots\right)$. Then $b^{0}\left(\eta^{t-1}, x_{t}\left(i^{t}\right), f_{t}\left(i^{t}\right), b_{t}\left(i_{t+1}, i^{t}\right) ; i^{t}\right)$ is the bequest that the head leaves to player $i^{t}$ in period $t$ is the history up to period $t-1$ is $\eta^{t-1}$ and $i^{t}$ takes action $\left(x_{t}\left(i^{t}\right)\right.$, $\left.f_{t}\left(i^{t}\right), b_{t}\left(i_{t+1}, i^{t}\right)\right)$. We do not restrict $b^{0}$ to be non-negative.

It's best to think of $b^{0}$, as the result of setting up a trust, with detailed descriptions of subsidies, when they apply, etc. For example, it might give a specific payout for any direct descendant finishing college.

In period $t>0$, all members of the dynasty alive at the time take as given the history up to that point, denoted by $h^{t-1}$ and including both $\eta^{t-1}$ and $b^{0}$, and make simultaneous and independent decisions about their own consumption, their own fertility, and any bequests that they wish to leave to their direct descendants. These are denoted by $x_{t}\left(i^{t}\right) \in \mathbb{R}^{k}, f_{t}\left(i^{t}\right) \in F=$ $\{0,1\}^{\bar{f}}$ and $b_{t}\left(i_{t+1}, i^{t}\right) \in \mathbb{R}^{f}$, respectively. We assume that if $f_{t}\left(i_{t+1}, i^{t}\right)=0$, then $b_{t}\left(i_{t+1}, i^{t}\right)=0$ as well.

We assume that the actions taken by player $i^{t}$ in period $t$ are constrained to satisfy

$$
\begin{aligned}
& p_{t} x_{t}\left(i^{t}\right)+c\left(f_{t}\left(i^{t}\right)\right)+\sum_{i_{t+1}=0}^{\bar{f}} b_{t}\left(i_{t+1}, i^{t}\right) \\
& \leq p_{t} e_{t}\left(i^{t}\right)+b_{t-1}\left(i_{t}, i^{t-1}\right)+b^{0}\left(\eta^{t-1}, x_{t}\left(i^{t}\right), f_{t}\left(i^{t}\right), b_{t}\left(i_{t+1}, i^{t}\right) ; i^{t}\right) .
\end{aligned}
$$


The action of player 0 must satisfy

$$
p_{0} x_{0}+\sum_{t} \sum_{i^{t}} b^{0}\left(\eta^{t-1}, x_{t}\left(i^{t}\right), f_{t}\left(i^{t}\right), b_{t}\left(i_{t+1}, i^{t}\right) ; i^{t}\right)+c\left(f_{0}\right) \leq p_{0} e_{0}
$$

for all $h^{t}$.

Let $z^{\infty}$ denote a complete description of the levels of consumption and fertility for every player for every time period, and denote by

$$
\hat{z}^{\infty}=\left(\hat{x}_{0}, \hat{f}_{0}, \hat{x}_{1}(1), \hat{f}_{1}(1), \ldots, \hat{x}_{1}(\bar{f}), \hat{f}_{1}(\bar{f}), \ldots\right)
$$

that history that maximizes the utility of player 0 , i.e., $u_{0}\left(\hat{z}^{\infty}\right) \geq u_{0}\left(z^{\infty}\right)$ for every other feasible path through the tree, $z^{\infty}$. Further, assume that $\hat{z}^{\infty}$ is the unique maximizer of $u_{0}$; that is, if $z^{\infty}$ is feasible and $z^{\infty} \neq \hat{z}^{\infty}$ then $u_{0}\left(\hat{z}^{\infty}\right)>u_{0}\left(z^{\infty}\right)$

Consider the family of bequest functions given by the following: If $\left(\eta^{t-1}, x_{t}\left(i^{t}\right), f_{t}\left(i^{t}\right), b_{t}\left(i_{t+1}, i^{t}\right)\right)=\left(\hat{\eta}^{t-1}, \hat{x}_{t}\left(i^{t}\right), \hat{f}_{t}\left(i^{t}\right), \hat{b}_{t}\left(i_{t+1}, i^{t}\right)\right)$, then

$$
\begin{aligned}
& b^{0}\left(\eta^{t-1}, x_{t}\left(i^{t}\right), f_{t}\left(i^{t}\right), b_{t}\left(i_{t+1}, i^{t}\right)\right) \\
= & p_{t} x_{t}\left(i^{t}\right)+c\left(f_{t}\left(i^{t}\right)\right)+b_{t}\left(i_{t+1}, i^{t}\right)-\left(p_{t} e_{t}\left(i^{t}\right)+b_{t-1}\left(i_{t}, i^{t-1}\right)\right),
\end{aligned}
$$

and if $\left(\eta^{t-1}, x_{t}\left(i^{t}\right), f_{t}\left(i^{t}\right), b_{t}\left(i_{t+1}, i^{t}\right)\right) \neq\left(\hat{\eta}^{t-1}, \hat{x}_{t}\left(i^{t}\right), \hat{f}_{t}\left(i^{t}\right), \hat{b}_{t}\left(i_{t+1}, i^{t}\right)\right)$, then

$$
b^{0}\left(\eta^{t-1}, x_{t}\left(i^{t}\right), f_{t}\left(i^{t}\right), b_{t}\left(i_{t+1}, i^{t}\right)=-\left[p_{t} e_{t}\left(i^{t}\right)+b_{t-1}\left(i_{t}, i^{t-1}\right)\right] .\right.
$$

Note that under this specification, if at any time any player deviates from the path $\hat{\eta}^{\infty}$, then for that player, and for all subesquent generations, the only feasible choice is to have $x=0$, and $f=(0,0, \ldots, 0)$.

Assumption 9 If $z$ is a sequence of consumptions and fertilities throughout the tree, such that $x_{i}=0$ and $f_{i}=(0,0, \ldots, 0)$, then $u_{i}(z)=0$. 
That is, if a player has no consumption and no children, his utility is independent of the allocations received by other members of the dynasty. (The choice of 0 is just a normalization, but we are assuming that it is 0 no matter what happens to what other people.)

Assumption $10 u_{i}\left(\hat{z}^{\infty}\right)>0$ for all $i \in I\left(\hat{z}^{\infty}\right)$.

Proposition 7 Under Assumptions 9 and 10, $\hat{z}^{\infty}$ is a subgame perfect equilibrium outcome of the game. It is also the unique subgame perfect equilibrium outcome that is the limit of subgame perfect equilibria of the finite horizon truncations of the game.

The proof is immediate and is not included.

\section{$5.3 \quad$ Examples}

In this section, we give a variety of examples to illustrate why equilibria may fail to be efficient. ${ }^{10}$ Keeping with the spirit of this section, we focus on inefficiencies originating within a dynasty. That is, all examples have at least one dynasty that in equilibrium is not dynastically maximizing given prices. Section 6 will look at instances in which an equilibrium fails to be efficient despite maximizing behavior of all dynasties.

At the beginning of Section 5, we said that an equilibrium in this environment would involve a mixture of Nash and Walrasian equilibrium as it always involves a game among family members as well as market transactions across

\footnotetext{
${ }^{10}$ See also Becker and Murphy (1988) for a discussion of situations in which equilibria may be inefficient.
} 
dynasties. In particular, we focus on subgame perfect Nash equilibria. The exact properties of such an equilibrium will depend on the details of the game, in particular, on the action space of the agents. To further clarify this equilibrium concept, we will define action sets and the equilibrium concept in detail for the first example. For the subsequent examples, many of the details are omitted.

\subsubsection{Credit Constrained Dynasties}

In Section 5.1 we emphasized that allowing parents to make negative bequests to their children is a crucial assumption to guarantee efficiency of the equilibrium in the Barro-Becker model. Following is a simple 2-period example illustrating why this is a necessary assumption. There are two dynasties, indexed by their period 0 members, $i \in \mathcal{P}_{0}=\{1,2\}$. Assume $\bar{f}=1$ so that each dynastic head can have at most one child. Then $\mathcal{P}_{1}=\{(1,1),(2,1)\}$. The dynasties differ in their labor endowment profiles. The labor endowments of the first dynasty are $\ell_{1}^{e}=1, \ell_{(1,1)}^{e}=0$, whereas the second dynasty has the reversed profile, $\ell_{2}^{e}=0, \ell_{(2,1)}^{e}=1$. The utility functions for the dynastic heads $i=1,2$ are $u_{i}(z)=c_{i}^{\sigma}+\beta c_{(i, 1)}^{\sigma}$, while children care about their own consumption only, $u_{(i, 1)}(z)=c_{(i, 1)}^{\sigma}$. The utility of being unborn is normalized to the utility of zero consumption. Let $1>\sigma>0$. A linear technology transforms labor into the consumption good, $F\left(\ell^{f}\right)=a \ell^{f}$. There is no capital and no storage technology. There is a small cost of having a child, $\theta>0$.

The actions of each (potential) agent are constrained to be in the respective budget set. Let $w_{0}, w_{1}$ be the period 0 and 1 wages, respectively, and let $R$ be 
the gross interest rate. Then the budget set for the period 0 agents is $B_{i}\left(w_{0}, R\right)=\left\{\left(c_{i}, b_{i}, f_{i}, \ell_{i}\right) \mid c_{i}+b_{i}+f_{i} \theta \leq w_{0} \ell_{i}, \ell_{i} \leq \ell_{i}^{e}, \ell_{i}, c_{i}, b_{i} \geq 0, f_{i} \in\{0,1\}\right\}$ and for the period 1 agents,

$$
B_{(i, 1)}\left(w_{1}, R, b_{i}\right)=\left\{\left(c_{(i, 1)}, \ell_{(i, 1)} \mid c_{(i, 1)} \leq w_{1} \ell_{(i, 1)}+R b_{i}, \ell_{(i, 1)} \leq \ell_{(i, 1)}^{e}, c_{(i, 1)} \geq 0\right\} .\right.
$$

An equilibrium is an allocation and prices $\left(w_{0}, w_{1}, R\right)$ such that

1. For $i=1,2$ the following holds:

(a) $\left(c_{i}, b_{i}, f_{i}, \ell_{i}\right) \in B_{i}\left(w_{0}, R\right)$

(b) $\left(c_{(i, 1)}, \ell_{(i, 1)}\right) \in B_{(i, 1)}\left(w_{1}, R, b_{i}\right)$

(c) $\left(c_{i}, b_{i}, f_{i}, \ell_{i}, c_{(i, 1)}, \ell_{(i, 1)}\right)$ is a subgame perfect Nash equilibrium of the game between players $i$ and $(i, 1)$.

2. Profit maximization: $w_{0}=w_{1}=a$

3. Market clearing:

goods market in period 1: $c_{1}+c_{2} \leq F\left(\ell_{1}+\ell_{2}\right)$

goods market in period 2: $c_{(1,1)}+c_{(2,1)} \leq F\left(\ell_{(1,1)}+\ell_{(2,1)}\right)$

bond market: $b_{1}+b_{2}=0$

The only equilibrium allocation of this example is quite degenerate:

$$
z=\left\{c_{1}=1, f_{1}=f_{2}=0, c_{2}=c_{(1,1)}=c_{(2,1)}=0\right\}
$$

The corresponding equilibrium prices are $w_{1}=w_{2}=a, R=0$. To see why this is an equilibrium, recall that bequests are constrained to be positive. In 
equilibrium, the second dynasty has an income of 0 in period 1 , and cannot borrow against the income of the child. This implies that the only feasible fertility choice is $f_{2}=0$. For dynasty 1 , the interest rate $R=0$ means that for any bequest choice $c_{(1,1)}=0$. This together with $\theta>0$ implies an optimal fertility choice $f_{1}=0$.

For small $\theta$ or large $\beta$, this equilibrium is $\mathcal{P}$ - as well as $\mathcal{A}$ - inefficient, because the following allocation is superior in both senses:

$$
\hat{z}=\left\{f_{1}=f_{2}=1, c_{1}=c_{2}=\frac{1-2 \theta}{2}, c_{(1,2)}=c_{(2,1)}=0.5\right\}
$$

The intuition is that not allowing negative bequests effectively rules out interdynasty trade in equilibrium. Both dynasties would be better off if the first dynasty would lend some of its period 1 income to the second dynasty. This example illustrates that preventing parents from leaving debt to their children reduces a dynasty's ability to borrow.

\subsubsection{Inability of Parent to Consume from Child's Income}

The next example illustrates an issue that comes up in a slightly more general formulation. In this example the parent lives for two periods and is not altruistic. The lack of altruism means that there is no benefit from having children, so equilibrium fertility is zero. The child would like to compensate the parent for the costs of childbearing. But this does not happen in equilibrium because of a commitment problem. Hence, the equilibrium is dynastically inefficient.

Suppose people live for two periods. The utility function of an agent born in $t$ is $u_{t}=c_{t}^{\sigma}+\beta c_{t+1}^{\sigma}$. Each agent is endowed with one unit of labor when young; there is no utility from leisure. The production function is $F(K, L)=$ 
$K^{\alpha} L^{(1-\alpha)}$. Assume capital depreciates fully after one period $(\delta=1)$. Agents can have children when young, it $\operatorname{costs} \theta$ units of the consumption good to produce one child. Let $f_{t}$ denote the number of children a person born in $t$ has. Parents can leave bequests to their children, but they are restricted to be nonnegative. Hence, the budget constraint for a young agent is $c_{t}^{y}+f_{t}(\theta+$ $\left.b_{t+1}\right) k_{t+1} \leq w_{t}+b_{t}$ and for an old agent $c_{t+1}^{o} \leq 1+r_{t} k_{t+1}$.

Claim: There exists a Competitive Equilibrium with $c_{0}^{o^{*}}=0, f_{0}^{*}=0$, $b_{1}^{*}=0, r_{1}^{*}=0$, and $k_{1}^{*}=0$. Thus, there are no agents alive beyond period 0.

Proof: To verify that this is an equilibrium, we need to find prices such that the allocation is consistent with consumer optimization and profit maximization. Consider the consumer first. Given $r_{1}^{*}=0$ and $\delta=1$, the return on savings is zero; hence, there is no incentive to save, and $k_{1}^{*}=0$ follows immediately. The return on children is also zero (assuming negative bequests are not possible). Therefore, since children are costly, the utility-maximizing number of children is $f_{0}^{*}=0$. Since the consumer has no income in period 1 , it follows that $c_{1}^{o^{*}}=0$.

Next, consider firm optimization:

$$
\max _{L, K} Y-w^{*} L-r^{*} K=\max _{L, K} F(K, L)-w^{*} L
$$

The only wage at which the profit-maximizing output is $Y=0$ is $w^{*}=\infty$. And given $w^{*}=\infty$, the above is indeed an equilibrium.

The above is an example of a model where fertility is $\mathcal{P}$-inefficiently low in equilibrium. Everyone could be made strictly better off by having some children, but no one would privately choose to do so. This problem results from the assumed form of the ownership structure. The return to an additional 
unit of labor is infinity, and the cost is finite, yet no one "produces" extra labor (that is, children), because the returns belong to someone else (the child). This issue would not arise if parents were allowed to make negative bequests to their children. Leaving a negative bequest to the child would allow a parent to reap the returns from producing an additional unit of labor. The private benefit from having a child would then no longer differ from the social return.

\subsubsection{Children and Drugs}

However, simply allowing negative bequests is not always enough to eliminate an inefficiency of the above kind. In some environments, an even richer bequest structure would be necessary to ensure that the dynamic game played within the family leads to an efficient outcome. Following is an example of this point.

There is one initial old person and one potential child, $\mathcal{P}=\{1,(1,1)\}$. The parent derives utility from her own consumption and from the consumption of her child: $u_{1}=u\left(c_{1}\right)+f_{1} \beta u\left(c_{(1,1)}\right)$, where $u(\cdot)$ is strictly concave. The child has preferences over consumption, $c_{(1,1)}$, and drugs, $d_{(1,1)}: u_{(1,1)}=c_{(1,1)}+\gamma d_{(1,1)}$. People in each period are endowed with one unit of leisure. A static technology converts labor into consumption and drugs, $c+d \leq F(\ell)=w \ell$. It $\operatorname{costs} \theta$ units of the consumption good to produce a child. Suppose $\gamma>1$, then $(1,1)$ (if born) will consume only drugs and none of the consumption good. Then the following is an equilibrium allocation: $z=\left\{c_{1}=w, f_{1}=0, c_{(1,1)}=0, d_{(1,1)}=\right.$ $0\}$. The reason for not having children is that knowing that their children will be drug addicts, parents prefer not to have any children. But note that, assuming $\theta$ is not too large, $z$ is not $\mathcal{P}$-efficient, since the following allocation is $\mathcal{P}$-superior: $\hat{z}=\left\{c_{1}=w-\theta, f_{1}=1, c_{(1,1)}=w, d_{(1,1)}=0\right\}$. 
Note that the above inefficiency does not disappear with negative bequests. Instead, the parent would need a tax-and-transfer system so that she can discourage the use by the child of the good the parent does not want the child to consume. Also note that more subtle disagreements between generations can cause similar issues. A very natural form of dissent would arise if parents and grandparents differ in their evaluation of their child/grandchild.

\subsubsection{Time Inconsistent Preferences and Efficiency}

The last two examples demonstrated that preferences that are time inconsistent across generations often lead to inefficient equilibrium outcomes. However, this does not have to be the case. This section gives an example of an efficient equilibrium in the presence of time inconsistent preferences. This example is interesting because it does not maximize the utility of the initial generation and therefore is very different from the Barro-Becker model.

Assume there is one dynasty, lasting for two periods. Hence, $\mathcal{P}=\{1,(1,1)\}$. There are three goods: leisure, a consumption good, and drugs. Each agent is endowed with one unit of leisure. A technology uses labor and produces both the consumption good and drugs, $c+d \leq F(\ell)=w \ell$. The cost of having a child is $\theta>0$. There is no storage technology; hence, it is impossible for the parent to leave a bequest. The utility function of the parent is

$$
\ln \left(c_{1}\right)+f \ln \left(c_{(1,1)}\right)
$$

and the child,

$$
\ln \left(c_{(1,1)}\right)+\ln \left(d_{(1,1)}\right)
$$

For small $\theta$, the equilibrium of this game is straightforward: 


$$
z=\left\{c_{1}=w-\theta, f=1, c_{(1,1)}=d_{(1,1)}=\frac{w}{2}\right\} .
$$

This obviously does not maximize the parent's welfare. The parent and the child disagree about the child's consumption of drugs. But this disagreement does not lead to an inefficiency in this example, because any other allocation would make the child strictly worse off. Note that the same would not be true if there were a storage technology and making bequests possible. In that case, the time inconsistency would indeed lead to an inefficiency.

\section{Is Population Growth Too High?}

In many discussions, it is taken as a given by policy makers that fertility is 'too high' in developing countries. Few reasons are typically given for this view, although several auxiliary concerns are mentioned. These include the overall scarcity of factors as well as the role of population size and density in determining pollution. In this section, we use the tools developed above to identify which of these concerns do and do not give rise to suboptimal population growth rates.

\subsection{Scarce Factors, Crowding, and Efficient Fertility}

If land is scarce, or if there are other fixed factors, will there be too many people in a competitive equilibrium? In the policy debate it is often argued that because resources are scarce, fertility decisions affect society as a whole and should therefore not be left entirely to individuals. The logic provided is that since parents do not take into account that having another child decreases 
the land available per capita for the next generation, private and social costs of an extra child do not coincide, and hence an inefficiency arises. This logic is sometimes used to justify family planning programs.

In this section we argue that this logic is a fallacy. The effect that an additional child has on wages (by increasing the aggregate labor supply) is analogous to the effect that an individual's increase in labor supply has on aggregate labor and thereby wages. These effects are channeled through prices and therefore do not lead to an inefficiency. Thus, this is an example of a pecuniary externality.

To see this, consider an example in which there are three goods in each period. The first is land, the second is leisure, and the third is a consumption good. All agents are endowed with one unit of leisure, which they supply inelastically to firms if they are born. Those agents alive in period 0 , indexed by $i=1, \ldots, N$, are also endowed with holdings of land, $A^{i}$. Let $\bar{A}=\sum_{i \in \mathcal{P}_{0}} A_{i}$ These holdings are sold to the firm and subsequently used forever. The production function is static with:

$$
y_{t}=F\left(A, \ell^{f}\right)
$$

where $F$ is assumed to be constant returns to scale.

Profit maximization on the part of the firm then implies that the dynastic $\mathcal{P}$-equilibrium price of land traded in period 0 is given by

$$
q_{0}=\sum_{t} F_{A}\left(\bar{A}, N_{t}\right) p_{t}
$$

where $N_{t}$ is the size of the population in period $t$ and $p_{t}$ is the equilibrium period 0 price of one unit of the consumption good in period $t$. Similarly, the real wage rate must be

$$
w_{t} / p_{t}=F_{\ell}\left(\bar{A}, N_{t}\right) .
$$


Thus, in keeping with intuition, if, for whatever reason, $\hat{N}_{t}>N_{t}$ for all $t$, and with $p_{t}$ held fixed, the sale price of land (and the implicit rental price as well) is higher while the equilibrium real wage rate must be lower. That is, because land is scarce, if parents choose to have more children, real wages must be lower. In this sense, one parent would, across equilibria, lower the realized wage for all children by increasing his fertility choice. In this sense, there is crowding of scarce resources.

Despite this fact, it is easy to see that all of the assumptions of Proposition 5 are satisfied. It follows that the equilibrium fertility levels chosen will be sequentially $\mathcal{P}$-efficient (and hence $\mathcal{P}$-efficient) as long as individual dynastic decision making is done efficiently.

To get some intuition for the above result, consider the following question: Is it possible to eliminate some agent $i$ at time $t$ from the equilibrium allocation to make the remaining $N_{t}-1$ people strictly better off due to their increased wages? To see that this is impossible, consider total output at time $t$ minus the compensation that $i$ receives for his labor input: $F\left(\bar{A}, N_{t}\right)-w$. In equilibrium $w=F_{N}$. This, together with the assumption that $F\left(\bar{A}, N_{t}\right)$ is concave in $N_{t}$, implies immediately that $F\left(\bar{A}, N_{t}\right)-w$ is greater than total output without $i, F\left(\bar{A}, N_{t}-1\right)$. Hence, it is impossible to make the remaining $N_{t}-1$ agents strictly better off because while less labor leads to higher wages, it at the same time it decreases returns to the fixed factor by even more.

Note that this result holds independent of the form of preferences. Thus, although the Barro-Becker formulation is one example in which this result is true, the conclusion is actually much more general. 


\subsection{Pollution, Congestion, and External Effects Across Families}

In contrast to the example presented above, if there are true external effects, equilibrium fertility need not be efficient. Recall, however, from Proposition 2 that under relatively weak assumptions, no $\mathcal{P}$-superior allocation can involve fewer people. So with negative externalities, the equilibrium can only involve inefficiently many people in the $\mathcal{A}$-sense and not the $\mathcal{P}$-sense, unless one is willing to violate these assumptions. If positive externalities are present in an economy, then the equilibrium fertility can be low fertility, in both the sequential and the $\mathcal{P}$-sense. Following is a simple example to illustrate these points. ${ }^{11}$

Assume that there are $N$ dynasties, each identical, each lasting only two periods. There are two goods, leisure and a consumption good, with a constant returns to scale production function between the two given by $c=w \ell$. Also assume that with each unit of output, one unit of pollution is produced and assume that labor is inelastically supplied. The time endowment, if born, is 1 .

Under this specification, it follows that if each dynasty has $f$ children, consumption in the second period is

$$
c_{(i, j)}=w \quad i=1, \ldots, N \quad j=1, \ldots, f_{i} .
$$

Thus, the total amount of pollution in period 2 is $s_{2}=\sum_{i} f_{i}$.

Assume that the utility function of individuals in the first generation is given by

$$
u_{i}\left(c_{i}, f_{1}, f_{2}, \ldots, \bar{f}, c_{(i, 1)}, c_{(i, 2)}, \ldots, c_{(i, \bar{f})}, s_{2}\right)=c_{i}+\beta \sum c_{(i, 1)}+\eta s_{2} .
$$

\footnotetext{
${ }^{11}$ A similar example is constructed in Harford (1998).
} 
We are interested in pollution here, so assume $\eta<0$. The utilities of agents alive in period 2 are given by:

$$
u_{(i, j)}\left(c_{i}, f_{1}, f_{2}, \ldots, \bar{f}, c_{(i, 1)}, c_{(i, 2)}, \ldots, c_{(i, \bar{f})}, s_{2}\right)=\beta c_{(i, j)}+\eta s_{2} .
$$

The utility of unborn is normalized to 0 .

The cost of bearing a child is $\theta>0$. The problem of an individual in period 0 making the fertility choice can be written as

$$
\max _{f} w+f(\beta w-\theta)+\eta s_{2}
$$

If we assume that $\beta w-\theta>0$, the parent will always choose to have the maximum number of children, $f^{*}=\bar{f}$. By symmetry, the same is true for all dynasties, which leads to an equilibrium level of pollution given by $s_{2}^{*}=N \bar{f}$. The equilibrium utility of a period 1 agent is therefore

$$
u\left(z^{*}\right)=w+\bar{f}(\beta w-\theta+\eta N) .
$$

It is clear that as long as $\beta w-\theta+\eta N<0$, that is, if $\eta<0$ is large enough in absolute value, then all parents can be made strictly better off by lowering utility to $f=0$ for everyone. Hence, in this case, the equilibrium allocation, $z^{*}$, is not sequentially $\mathcal{P}$-efficient. However, $z^{*}$ will be $\mathcal{P}$-efficient as long as $\beta w+\eta N>0$, that is, as long as being alive and enduring the externality is better than not being alive. On the other hand, if $\beta w+\eta N<0$, then the potential children would also gain by not being born, and for this case $z^{*}$ is not $\mathcal{P}$-efficient.

Finally, consider a positive externality, $\eta>0$. This is relevant, for example, in models with human capital if there are positive external effects in knowledge accumulation. (See Romer (1987) and Lucas (1988) for examples.) Assume 
now that $\beta w-\theta<0$; that is, the private returns on having a child are negative. Then in equilibrium, $f^{*}=0$. Suppose further that $\beta w-\theta+\eta N>0$; then the social returns on having a child are higher than the private returns. Thus, the equilibrium is not efficient in either sense. The allocation $\hat{f}=\bar{f}$ is strictly superior both in the sequential and in the $\mathcal{P}$-sense, since it gives strictly higher utility to everyone in the economy, parents and children.

The above examples show that it is far from obvious that fertility is too high in Africa and too low in Sweden. Per-person pollution, for example, is likely to be much higher in rich countries compared to poor ones. This would imply that the negative externality is a bigger problem in Sweden, implying that the Swedes that are having too many babies. However, if the positive externality is important, then perhaps people in all countries are having too few children.

\subsection{Missing Markets}

Yet another example of the failure of the first welfare theorem in this environment arises when key markets are missing. One can imagine many examples relevant in fertility settings (for example, the lack of insurance against the risk of not being able to have children). A simple and particularly interesting example involves private information about expected lifetimes. This is a common explanation given for the relative sparsity of annuity markets. This may lead parents to have too many children, because parents use children as an alternative to annuity contracts. In other words, an $\mathcal{A}$-superior allocation would involve fewer people with better insurance across dynasties. The miss- 
ing markets problem is similar to the pollution externality discussed above. In both cases, dynasties may well be $\mathcal{A}$-maximizing, and yet, equilibrium fertility is too high due to a problem in the economy as a whole.

\section{Conclusion}

In this paper, we have presented three extensions of the notion of Paretooptimality for models in which fertility is endogenous, $\mathcal{P}$-efficiency, $\mathcal{A}$-efficiency, and sequential $\mathcal{P}$-efficiency. We have shown that, although these models always have external effects, if they are confined to the family and the family makes optimal decisions, the time series of populations that is generated is optimal. We have shown that the most popular economic model of fertility choice, that of Barro and Becker (1989), satisfies these assumptions, and hence, in that model, population is efficient. Finally, we have shown that the presence of external effects can cause indivdually optimal fertility choices to be suboptimal from a social point of view and that this bias depends on the direction of the external effect. 


\section{References}

[1] ALVAREZ, F. and N. L. STOKEY (1998), "Dynamic Programming with Homogeneous Functions," Journal of Economic Theory, 82, 167-189.

[2] BARRO, R. J. and G. S. BECKER (1989), "Fertility Choice in a Model of Economic Growth," Econometrica, 57, (2), 481-501.

[3] BECKER, G. S. and R. J. BARRO (1988), "A Reformulation of the Economic Theory of Fertility," Quarterly Journal of Economics, 103 (1), $1-25$.

[4] BECKER, G. S. and K. M. MURPHY (1988), "The Family and the State," Journal of Law and Economics, 31 (1), 1-18.

[5] BENTHAM, J. (1948), An Introduction to the Principle of Morals and Legislation, Oxford: Blackwell (revision of 1823 edition).

[6] BEWLEY, T. F. (1972), "Existence of Equilibria in Economies with Infinitely Many Commodities," Journal of Economic Theory, 43, 514-540.

[7] BLACKORBY, C., W. BOSSERT, and D. DONALDSON (1995), "Intertemporal Population Ethics - Critical-Level Utilitarian Principles," Econometrica, 63 (6), 1303-1320.

[8] BLACKORBY, C., W. BOSSERT, and D. DONALDSON (2002), "Utilitarianism and the Theory of Justice," in Handbook of Social Choice and Welfare, Volume 1, edited by Arrow, K. J., Sen, A. K. and K. Suzumura. Amsterdam: Elsevier Science, North-Holland. 
[9] BOLDRIN, M. and L. E. JONES, (2002), "Mortality, Fertility and Savings Decisions," Review of Economic Dynamics, 5 (4), 775-814.

[10] CHOMITZ, K. M. and N. BIRDSALL (1991), "Incentives for Small Families: Concepts and Issues," in "Proceedings of the World Bank Annual Conference on Development Economics 1990," Washington D.C., World Bank, 309-339.

[11] DEBREU, G. (1959), Theory of Value: An Axiomatic Analysis of Economic Equilibrium, New York: Wiley.

[12] DOEPKE, M. (2001), "Accounting for Fertility Decline During the Transition to Growth," Department of Economics Working Paper 804, UCLA.

[13] FERNANDEZ-VILLAVERDE, J. (2001), "Was Malthus Right? Economic Growth and Population Dynamics," Working Paper, University of Pennsylvania.

[14] FRIEDMAN, D. (1972), "Laissez-Faire in Population: The Least Bad Solution," Occasional Paper of the Population Council, New York.

[15] GOLOSOV, M., L. E. JONES and M. TERTILT (2003), "Appendix to Efficiency with Endogenous Population Growth," available at http://www.econ.umn.edu/ lej/lejresearch.html.

[16] HARFORD, J. D. (1998), "The Ultimate Externality," American Economic Review, 88 (1), 260-265. 
[17] JONES, L. E. and R. E. MANUELLI (1990), "A Convex Model of Equilibrium Growth: Theory and Policy Implications," Journal of Political Economy, 98 (5), 1008-1038.

[18] LEE, R. D. and T. MILLER (1991), "Population Growth, Externalities to Childbearing, and Fertility Policy in Developing Countries," in "Proceedings of the World Bank Annual Conference on Development Economics, 1990." Washington, D.C.: World Bank, 275-304.

[19] LUCAS, R. E., Jr. (1988), "On the Mechanics of Economic Development," Journal of Monetary Economics, 22 (1), 3-42.

[20] MALThUS, T. P. (1798), "An Essay on the Principle of Population and Summary View of the Principle of Population," Reprint, Baltimore: Penguin, 1970.

[21] MICHEL, P. and B. WIGNIOLLE (2003), "On Efficient Child Making," mimeo, EUREQua Paris.

[22] MILL, J. S. (1965), "Principles of Political Economy," Reprints of Economic Classics. New York: Augustus M. Kelley (originally published in 1848).

[23] NERLOVE, M. and L. K. RAUT (1997), "Growth Models with Endogenous Population: A General Framework," in Handbook of Population and Family Economics, Vol. 1B, edited by M. R. Rosenzweig and O. Stark, Amsterdam: Elsevier Science, North-Holland. 
[24] NERLOVE, M., A. RAZIN, and E. SADKA (1987), "Household and Economy: Welfare Economics of Endogenous Fertility," Economic Theory, Econometrics and Mathematical Economics Series. Boston: Harcourt, Brace Jovanovich.

[25] NERLOVE, M., A. RAZIN, and E. SADKA (1989), "Socially Optimal Population Size and Individual Choice," in Economic Theory of Optimal Population, edited by K. Zimmermann.

[26] RAZIN, A. and E. SADKA (1995), Population Economics, Cambridge: MIT Press.

[27] ROMER, P., (1986), "Increasing Returns and Long-Run Growth," Journal of Political Economy, 94 (5), 1002-1037.

[28] SCHWEIZER, U. (1996), "Welfare Economics of Population Growth," Sonderforschungsbereich 303 Discussion Paper A535, Universitat Bonn.

[29] SCOTCHMER, S. (1997), "On Price-Taking Equilibria in Club Economies with Nonanonymous Crowding," Journal of Public Economics 65 (1), pp. $75-88$.

[30] SIMON, J. L. (1992), Population and Development in Poor Countries, Princeton: Princeton University Press.

[31] SINGER, P. (1993), Practical Ethics, Cambridge: Cambridge University Press.

[32] TERTILT, M. (2003), "Polygyny and Poverty," mimeo, Stanford University. 
[33] WILliS, R.J. (1987), "Externalities and Population," in Population Growth and Economic Development: Issues and Evidence, edited by G. Johnson and R. D. Lee, Madison: University of Wisconsin Press. 661-702.

[34] ZIMMERMANN, K. F. (1989), Economic Theory of Optimal Populations, Berlin - Heidelberg: Springer Verlag. 